\title{
The combined role of faceting and heteroatom doping for hydrogen evolution on a WC electrocatalyst in aqueous solution: a density functional theory study
}

\author{
Guang-Qiang Yu, Bo-Ying Huang, Si-Ming Chen, Jia-Wei Liao, \\ Wen-Jin Yin, Gilberto Teobaldi, Xi-Bo Li
}

\section{Published version information}

Citation: $\mathrm{G}$ Yu et al. 'The combined role of faceting and heteroatom doping for hydrogen evolution on a WC electrocatalyst in aqueous solution: a density functional theory study.' J Phys Chem C, vol. 125, no. 8 (2021): 4602-4613.

DOI: $10.1021 /$ acs.jpcc.0c11104

This document is the Accepted Manuscript version of a Published Work that appeared in final form in Journal of Physical Chemistry C, copyright (C2021 American Chemical Society after peer review and technical editing by the publisher. To access the final edited and published work see the DOI above.

Please cite only the published version using the reference above. This is the citation assigned by the publisher at the time of issuing the AAM. Please check the publisher's website for any updates. 


\title{
The Combined Role of Faceting and Hetero-Atom Doping for Hydrogen Evolution on a WC Electrocatalyst in Aqueous Solution: A Density Functional Theory Study
}

Guang-Qiang $\mathrm{Yu}^{1}$, Bo-Ying Huang ${ }^{1}$, Si-Ming Chen ${ }^{1}$, Jia-Wei Liao ${ }^{1}$, Wen-Jin Yin $^{2}$, Gilberto Teobaldi ${ }^{3,4,5}, \mathrm{Xi}-\mathrm{Bo} \mathrm{Li}^{1, *}$

1. Siyuan Laboratory, Guangzhou Key Laboratory of Vacuum Coating Technologies and New Energy Materials, Guangdong Provincial Engineering Technology Research Center of Vacuum Coating Technologies and New Energy Materials, Department of Physics, Jinan University, Guangzhou, Guangdong, 510632, China.

2. School of Physics and Electronic Science, Hunan University of Science and Technology, Xiangtan 411201, China.

3. Scientific Computing Department, STFC UKRI, Rutherford Appleton Laboratory, Harwell Campus, OX11 0QX Didcot, United Kingdom.

4. Stephenson Institute for Renewable Energy, Department of Chemistry, University of Liverpool, L69 3BX Liverpool, United Kingdom.

5. School of Chemistry, University of Southampton, Highfield, SO17 1BJ Southampton, United Kingdom

*Corresponding Email: lixibo@jnu.edu.cn

\begin{abstract}
Tungsten carbide (WC) is an established model electrocatalyst for the hydrogen evolution reaction (HER) in aqueous solutions. In spite of extensive interest in and work on this material, systematic atomistic understanding of the combined role of faceting and hetero-atom doping for hydrogen evolution on WC electrocatalysts in aqueous solution is not available. To fill this knowledge gap, here we explore the interplay of these parameters for the electrocatalytic performance of WC by means of Density Functional Theory (DFT) simulations. In our simulations, we explicitly account for solvent (water) effects and related electrochemical, potential dependent oxygen or hydroxyl (co-)adsorption on the WC surfaces as determined by analysis of surface Pourbaix diagrams. Among the several low-index WC surfaces screened, the DFT simulations indicate that the W-terminated (-100) and (111) surfaces of WC show comparable exchange currents of 3.908 and $0.133 \mathrm{~mA} / \mathrm{cm}^{2}$, respectively. The simulations also suggest that $\mathrm{V}$ or $\mathrm{N}$ doping can substantially increase the HER activity of some WCsurfaces to levels comparable to commercial $\mathrm{Pt} / \mathrm{C}$ electrocatalysts, with current densities as large as $10.555,1.730$, and $0.636 \mathrm{~mA} / \mathrm{cm}^{2}$ for the V-doped W-terminated (001), V-doped (101), and N-doped (101) WC-surfaces, respectively. The improved HER activities are rationalized in terms of the $d$-band or $p$-band center, which are both shown to be related to the capability of tuning the hydrogen adsorption, thence HER performance. The calculated strong dependence of the HER activity on the presence of electrochemical adsorption of oxygen and hydroxyls reiterates the importance of modeling realistic electrochemical conditions for WC pristine or doped surfaces. We expect the DFT results presented to provide timely and original guidelines for further theoretical and experimental studies of HER activity on WC-related electrocatalysts.
\end{abstract}


KEYWORDS: electrocatalysis, tungsten carbide, hydrogen evolution, surface Pourbaix diagram, doping

\section{INTRODUCTION}

Its high energy capacity, environmental benignity, and recycling properties make molecular hydrogen a promising energy carrier to solve existing and future energy concerns. One important route to hydrogen production is through electrochemical water splitting, with the necessary electrical current being ideally obtained from renewable sources e.g. sunlight or wind. The hydrogen evolution reaction (HER) is the reductive half-cell process of water splitting. Its slow kinetics demands suitable catalysts to boost the process and make it scalable. Although platinum (Pt) and platinum-based catalysts are considered to be the most efficient ones for the HER, the high cost of Pt has so far hindered large-scale industrial uptake of electrochemical water splitting. ${ }^{1-5}$ These elements make identification of alternative efficient, stable and scalable catalysts highly desirable in order to replace Pt, and sustain large-scale industrial uptake of electrocatalytic hydrogen production by water splitting. Great efforts have accordingly been dedicated to the exploration of alternative catalysts for the HER, based on non-noble transition-metal compounds, such as transition metal sulfides, carbides, nitride, and phosphides. ${ }^{6-23}$

Among these systems, tungsten carbide (WC) exhibits a platinum-like electronic structure, ${ }^{24}$ suggesting an HER activity potentially comparable to pure Pt. However, previous experiments have shown that WC results in a much lower HER activity by comparison to Pt. ${ }^{11,25-35}$ As the HER activity depends critically on the atomic and electronic structure of the surfaces exposed to the reactants, ${ }^{36-37}$ systematic study of the HER-performance of different WC facets is critical for understanding the origin of such underperformance and identification of strategies to improve it. Previous studies in the field have shown that selecting suitable dopants can increase the HER catalytic activity of tungsten carbide and molybdenum carbides in experiments. ${ }^{23,38}$ However, the theoretical studies available in the literature are all limited to one facet, and neglect the role of water for the electrocatalytic properties of the substrate. ${ }^{23}$, 38-39 These considerations prompt us to further explore in-silico, by Density Functional Theory (DFT), the role of doping for tuning the HER performance of WC. By extensive and systematic study of the role of faceting and doping for the HER with inclusion of water effects in the simulations, we uncover and quantify several atomic and electronic factors capable of modulating the HER-performance for WCbased electrocatalysts.

To this end, here we investigate the HER on eleven WC surfaces and their vanadium (V), manganese $(\mathrm{Mn})$ or nitrogen $(\mathrm{N})$ doped counterparts by DFT simulations, taking into account water effects. Thermodynamic screening of several, differently terminated facets of pristine and doped WC, with inclusion and neglect of solvent (water) effects, enables us to disentangle the combined role of faceting, electrochemical potential-dependent oxygen and hydroxyl coverages, thence local composition of the catalytic site, and hetero-atom doping for the emergent HER performance of the WC-surfaces studied. Besides demonstrating the importance of considering the water effect for the electrocatalytic performance and exchange current densities of WC-substrates, the results presented provide guidelines to increase the HER activity by $\mathrm{V}, \mathrm{Mn}$ and $\mathrm{N}$ doping of specific facets as well as atomistic and electronic structure arguments to understand the origin of such an increase. Given its extension and systematic nature, we believe the present results to be a valuable contribution to foster further experimental and theoretical research in electrocatalysts for the HER. 


\section{COMPUTATIONAL DETAILS}

Density functional theory (DFT) calculations were performed using the plane-wave Vienna ab initio simulation package (VASP). ${ }^{40}$ Spin polarization and van der Waals (vdW) corrections were accounted at the level of the optB86b-vdW method. ${ }^{41}$ The plane-wave energy cutoff was $400 \mathrm{eV}$. $10 \times 10 \times 10$ and $5 \times 5 \times 1$ Monkhorst-Pack ${ }^{42} \mathrm{k}$-point meshes were used for bulk and slabs calculations, respectively. The threshold for electronic self-consistency and geometry optimization was $10^{-5} \mathrm{eV}$ and $0.05 \mathrm{eV} / \AA$, respectively. All the WC surfaces were modeled using a $(2 \times 2)$ slabs with six atomic layers and a vacuum buffer of $10 \AA$ in the non-periodic direction. During the geometry optimization of the slabs, the four topmost atomic layers were allowed to relax while the two bottom ones were kept fixed in the bulk position.

In the heterogeneous electro-catalysis, activity and performance depend on the surface atomic composition and structure of the electro-catalysts. This can be modelled accurately provided the solvent (water) effect is included in the simulations, as possible via surface Pourbaix diagram (SPD) analysis. SPD analysis can produce detailed information on the amount of oxygen $(* \mathrm{O})$ or hydroxyl $(* \mathrm{OH})$ adsorbed on the catalytic surface as a function of both the applied electrochemical potential and the $\mathrm{pH}$ of the aqueous electrolyte. ${ }^{36-37,43-45}$ This analysis can reveal that the real catalytic surface at a given electrochemical potential may be not be the pristine, bare one but decorated with adsorbed ${ }^{*} \mathrm{O}$ or $* \mathrm{OH}$ species from the water electrolyte, as previously found in studies of the oxygen evolution on $\mathrm{Pt}, \mathrm{Ag}$, and $\mathrm{Ni}$, and of the hydrogen evolution on molybdenum carbides. ${ }^{36,43}$

Here, we mainly focus on the electrochemical conditions at which the HER happens, namely for an applied potential relative to reverse hydrogen electrode of zero Volts $\left(\mathrm{U}_{\mathrm{RHE}}=0\right)$ and strong acidic conditions. Since the chemical mechanisms through which the $\mathrm{pH}$ affects hydrogen evolution is complex and still in debate, our goal is not to solve such a debate. ${ }^{46-47}$ We rather aim to quantify the nexus between accurately modelled surface composition, geometry and electronic structure and the emerging HER activity.

To determine the stability of the surfaces substitutionally doping in the topmost layer $(\mathrm{X} /(h k l), \mathrm{X}=$ $\mathrm{Mn}, \mathrm{V}, \mathrm{N}$ ), we resort to the formation energy $E_{f}$ defined as follows:

$$
E_{f}=\left(E_{\mathrm{X} /(h k l)}-E_{(h k l)}-m \mu_{i}+m \mu_{j}\right) / m
$$

where $E_{\mathrm{X} /(h k l)}$ and $E_{(h k l)}$ are the total energies of the $\mathrm{X} /(h k l)$ and the $(h k l)$ slab, respectively. $\mu_{i}(i=\mathrm{N}, \mathrm{V}$ or $\mathrm{Mn})$ and $\mu_{j}(j=\mathrm{W}$ or $\mathrm{C})$ are the chemical potentials of the species $i$ and $j$ in their bulk states (the gas state for $\mathrm{N}$ ), respectively. $m$ is the number of the doping atoms.

To access the HER activity of a catalyst, the hydrogen adsorption ability is often introduced. The hydrogen adsorption ability should be close to zero for a good catalyst. Here, we consider the hydrogen adsorption ability through the hydrogen adsorption step (Volmer reaction) on a catalyst: $\mathrm{H}^{+}+\mathrm{e}^{-}+* \rightarrow$ ${ }^{*} \mathrm{H}$. The free-energy change of the adsorption hydrogen atom can be obtained as:

$$
\Delta G_{n \mathrm{H}}=\Delta E_{n \mathrm{H}}+\Delta E_{\mathrm{ZPE}}-\mathrm{T} \Delta S
$$

where $\Delta E_{n \mathrm{H}}=E[n \mathrm{H}]-E[(n-1) \mathrm{H}]-1 / 2 E\left[\mathrm{H}_{2}\right] . E[n \mathrm{H}]$ and $E[(n-1) \mathrm{H}]$ are the total energies of the surface with $n$ and $n-1$ hydrogen atoms adsorbed, respectively. $E\left[\mathrm{H}_{2}\right]$ is the total energy of a molecule of hydrogen $\left(\mathrm{H}_{2}\right)$ in the gas phase. The $\Delta E_{\mathrm{ZPE}}$ and $\mathrm{T} \Delta S$ are the zero-point energy and entropy contributions, respectively. As shown in Table S1, the zero-point energies of adsorbed hydrogen may be different on different catalyst as strongly sensitive to the chemical nature of the atom the $\mathrm{H}$ is adsorbed on. The entropy of hydrogen is $\Delta \mathrm{S}_{\mathrm{H}}=1 / 2 \mathrm{~S}_{\mathrm{H} 2}$, with $\mathrm{S}_{\mathrm{H} 2}$ being the entropy of $\mathrm{H}_{2}$ in the gas phase at standard conditions. The vibrational entropy for the adsorbed state is neglected in this study. 
In this work, the exchange current density is calculated as ${ }^{48}$

$$
i_{0}=-e k_{0} /\left[1+\exp \left(\left|\Delta G_{\mathrm{H}}\right| / k \mathrm{~T}\right)\right]
$$

where $k_{0}$ is a rate constant with the value of $200 \mathrm{~s}^{-1} \mathrm{site}^{-1} .{ }^{48}$ In order to reflect the HER activity in a more real case, $\Delta G_{\mathrm{H}}$ is taken from the corresponding value at the determined $\mathrm{H}$ coverage. ${ }^{48}$ In detail, the determined $\mathrm{H}$ coverage of a surface is also regarded as the stable $\mathrm{H}$ coverage during the HER, which is obtained according to hydrogen adsorption ability: $\mathrm{H}$ atom is much easier to desorb than to adsorb. ${ }^{36,48}$ Apart from where stated otherwise, the results presented have been calculated for $U_{\mathrm{RHE}}=0 \mathrm{eV}$ and $\mathrm{T}=$ $298.15 \mathrm{~K}$. According to previous work, $i_{0}$ reaches the vertex of the volcano and the catalytic activity achieves the best level of a catalyst when $\Delta G_{\mathrm{H}}$ approaches zero. ${ }^{48}$ We screen out the WC surfaces with $\Delta G_{\mathrm{H}}$ in between -0.10 and $+0.10 \mathrm{eV}$ since they have nearly thermoneutral hydrogen adsorption and could show larger $i_{0}$, or high HER activity.

\section{RESULTS AND DISCUSSIONS}

\subsection{Bulk, Bare Surfaces and Bare Doped Surfaces of WC}

Bulk WC (space group $\overline{\mathrm{C}} \overline{\mathrm{m}} 2$ ) contains one tungsten atom and one carbon atom in the hexagonal unit cell, shown in Figure 1a. Our DFT optimized lattice parameters are $\mathrm{a}=\mathrm{b}=2.911 \AA$, and $\mathrm{c}=2.842$ $\AA$, in good agreement with the experimental values of $\mathrm{a}=\mathrm{b}=2.906 \AA$, and $\mathrm{c}=2.837 \AA .{ }^{49-50}$ The calculated Density of States (DOS) of WC (Figure 1b) indicates metallicity and good electron conductivity, to the benefit of electron transfer during the HER process. The simulation suggest the electron conductivity of WC to be mainly contributed by W, due to its larger value of DOS near the Fermi level.

(a)

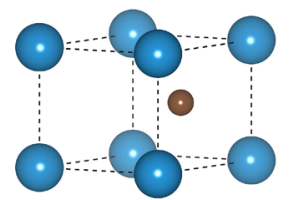

WC bulk

(b)

(c)
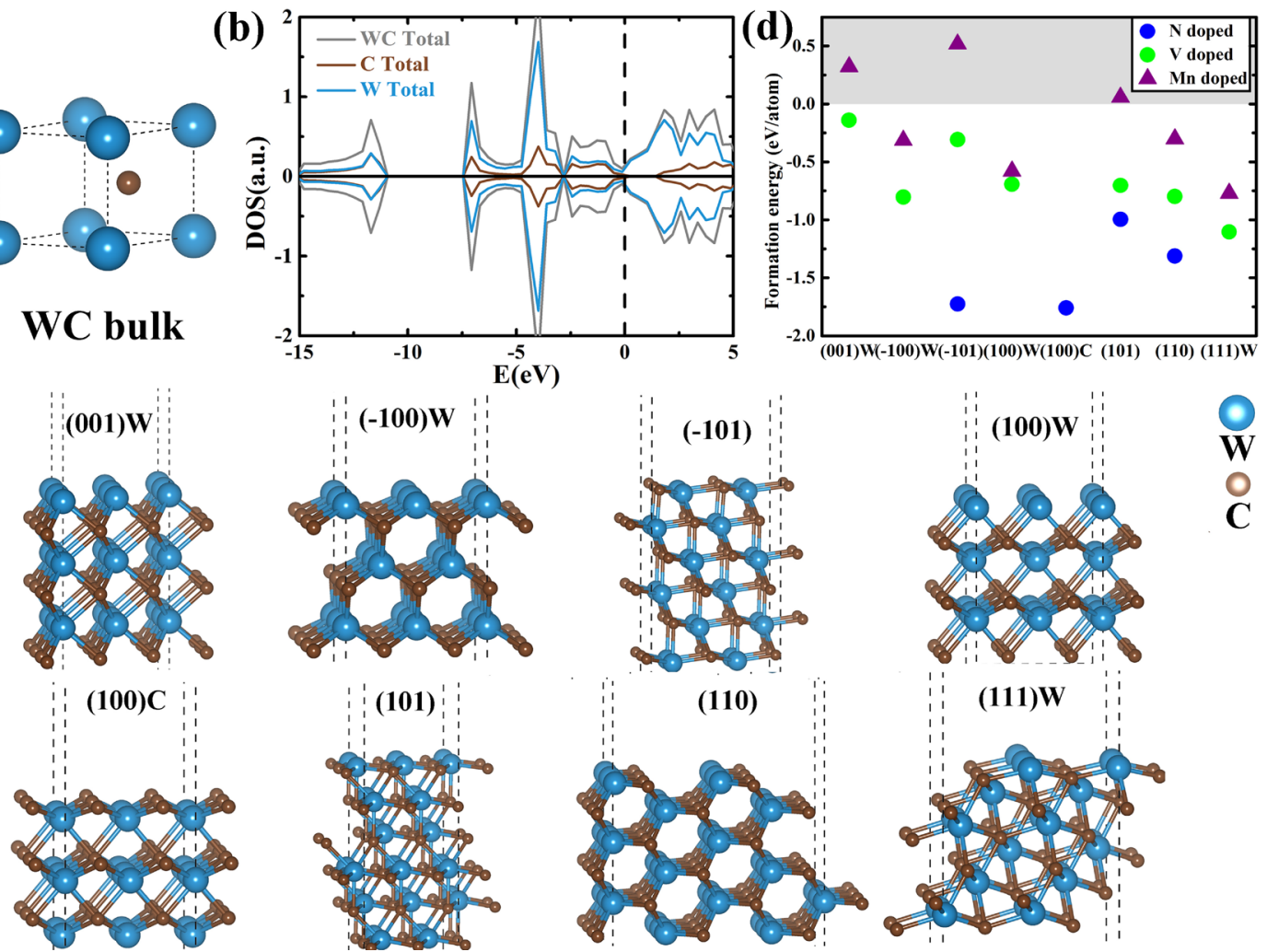

Figure 1. The (a) atomic structure and (b) calculated total density of states (DOS) of bulk WC. The vertical dashed line marks the position of the Fermi energy. (c) The atomic structure of the different lowindex WC surfaces considered. The dashed lines indicate the $(2 \times 2)$ slab periodicity in the calculations. (d) The DFT-calculated formation energy for $\mathrm{X} /(h k l)(\mathrm{X}=\mathrm{Mn}, \mathrm{V}$, or $\mathrm{N})$. The gray-shaded and white areas 
highlight stable (negative formation energy) and unstable (positive formation energy) $\mathrm{X} /(h k l)$ systems, respectively. The plotted data are listed in Table S2. Brown and blue spheres represent $\mathrm{C}$ and $\mathrm{W}$ atoms, respectively.

Starting from the bulk WC structure, we cleaved eleven different configurations of the low-index surfaces, and eight of them (Figure 1c) were selected for study of their HER-properties. Depending on the atoms exposed, these surfaces can be divided into three classes: those terminated by tungsten (W) atoms (e.g., (001)W), those terminated by carbon (C) atoms only (e.g., (100)C), and those showing mixed $\mathrm{W}$ and $\mathrm{C}$ termination (e.g., (-101)). The stability is vital to a catalyst. In addition, the three low-index surfaces discarded $((001) \mathrm{C},(-100) \mathrm{C}$ and $(111) \mathrm{C})$ were not studied, as these systems will adsorb oxygen atoms and then change largely when introducing the water effect at $U_{\mathrm{RHE}}=0 \mathrm{~V}$, as shown in Figure S1.

In order to study the effects of hetero-atom doping on the HER catalytic activity, the $\mathrm{W}$ and $\mathrm{C}$ atoms in the topmost layer of the eight WC surfaces were separately substituted by vanadium (V), manganese $(\mathrm{Mn})$ or nitrogen $(\mathrm{N})$ atoms. Figure $\mathbf{S 2}$ reports the optimized atomic structure of these doped systems. We use an $\mathrm{X} /(h k l)$ format where $X$ indicate the dopant $(X=\mathrm{Mn}, \mathrm{V}$, or $\mathrm{N})$ present at the topmost layer of the WC $(h k l)$ surface. The stability of the doped surfaces was evaluated by means of the corresponding formation energies (Figure 1d and Table S2): negative (positive) values indicate that the doped surfaces are stable and could (not) be easily (hardly) synthesized experimentally under thermodynamic equilibrium. The results show that all the N- and V-doped surfaces are stable. Conversely, only the (100)W, (100)W, (110) and (111)W Mn-doped surfaces are stable. The fifteen thermodynamically favored systems in Figure 1d were further studied by modelling their HER properties. In the absence of further oxygen or hydroxyl adsorption, these surface models are labeled as bare surfaces.

In the following, the surfaces determined by Surface Pourbaix Diagram (SPD) analysis at $\mathrm{U}_{\mathrm{RHE}}=0$ $\mathrm{eV}$ are defined as the real surfaces, which may be covered by $* \mathrm{O}$ or $* \mathrm{OH}$. In addition, the bare surfaces could also be the real surfaces, as it will be the case for the ${ }^{*} \mathrm{O}$ and ${ }^{*} \mathrm{OH}$ free $(100) \mathrm{C}$ surface in the following. We mainly focus on HER on real WC surfaces in this work.

\subsection{Hydrogen Evolution on WC Surfaces, and V, Mn, or N Doped Ones}

\subsubsection{Surface Pourbaix Diagrams and Hydrogen Evolution on WC Surfaces}

To investigate the effect of water on the WC surfaces, we calculate their SPDs as a function of the applied voltage $\mathrm{U}_{\mathrm{SHE}}$ (relative to the standard hydrogen potential) and $\mathrm{pH}$. The $\mathrm{H}$ coverage is defined as the ratio of the number of the adsorbed hydrogen atoms to the number of exposed atoms of the corresponding bare surface, in unit of ML (monolayer). The same definition is also applied to the coverage of * $\mathrm{O}$ or $* \mathrm{OH}$. The results of this analysis are shown in Figure 2. Analysis of the SPDs offer understanding of the $* \mathrm{O}$ and $* \mathrm{OH}$ adsorption (including the case of free of $* \mathrm{O}$ and $* \mathrm{OH}$ ) on the bare surfaces at different applied voltages $\mathrm{U}$ and $\mathrm{pH}$ in water. ${ }^{43,51-52}$ In the previous experimental and theoretical work, it is also indicated the non-metal catalysis covered by $* \mathrm{O}$ or $* \mathrm{OH}$ in the condition of $\mathrm{U}_{\mathrm{SHE}}=0, \mathrm{pH}=0 .{ }^{36,53-54}$ Here, the SPD of $(001) \mathrm{W}$ is taken as an example for discussion. For $\mathrm{U}_{\mathrm{RHE}}<-0.52 \mathrm{~V},(001) \mathrm{W}$ prefers to be free of $* \mathrm{O}$ and $* \mathrm{OH}$ adsorbates. In contrast, it will be favorable for the bare surface to be covered by $3 / 4 \mathrm{ML}$ $* \mathrm{O}$ and $1 / 4 \mathrm{ML} * \mathrm{OH}$ for $\mathrm{U}_{\mathrm{RHE}}$ in the range between $-0.52 \mathrm{~V}$ and $-0.15 \mathrm{~V}$. However, for $\mathrm{U}_{\mathrm{RHE}}>-0.15 \mathrm{~V}$, this surface will be preferentially covered by $1 \mathrm{ML} * \mathrm{O}$. The oxygen reduction reaction (ORR) and HER often take place at potentials of $0.90 \mathrm{~V}$ (RHE) and $0 \mathrm{~V}$ (RHE), respectively. For both these conditions, the DFT simulations predict the $(001) \mathrm{W}$ surface to be covered by $1 \mathrm{ML}$ adsorbed oxygen $(1 \mathrm{ML} * \mathrm{O}$ (001)W).

As shown in Figure 2, at the ORR potential of $0.90 \mathrm{~V}$ (RHE), all the WC surface will be covered 
by oxygen atoms or hydroxyls, specifically 1 ML oxygen on (001)W, (-100)W, (100)W and (100)C, 1/2 ML oxygen on (110), 1/2 ML hydroxyl on (-101), 3/8 ML oxygen and 1/8 ML hydroxyl on (101), 1/2 ML oxygen and 1/2 ML hydroxyl on (111)W. Although here we will not discuss the ORR, the present results could serve as a basis for further study of this reaction on WC surfaces.

The results of the simulations indicate that, at $0 \mathrm{~V}$ (RHE) potentials, all the $\mathrm{W}$ terminated surfaces will be covered by oxygen or hydroxyl: $1 \mathrm{ML}$ oxygen on (001)W and (100)W, 1/4 ML oxygen and 3/4 ML on $(-100) \mathrm{W}, 1 / 2 \mathrm{ML}$ oxygen and 1/2 ML on (111)W. All the surfaces with mixed W and C terminations will be covered by $1 / 2$ ML hydroxyl. The C-terminated (100)C surface will be covered by hydrogen atoms and free of oxygen and hydroxyl. Overall, these results indicate that the exposed $\mathrm{W}$ atoms in the top layers of WC surfaces facilitate ${ }^{*} \mathrm{O}$ and $* \mathrm{OH}$ adsorption at HER-relevant conditions. The adsorption sites and atomic structures of the oxidized and hydroxylated WC surfaces at $0 \mathrm{~V}$ (RHE) are as shown in Figure S3 and Figure S4. In the following we investigate their hydrogen evolution performance.
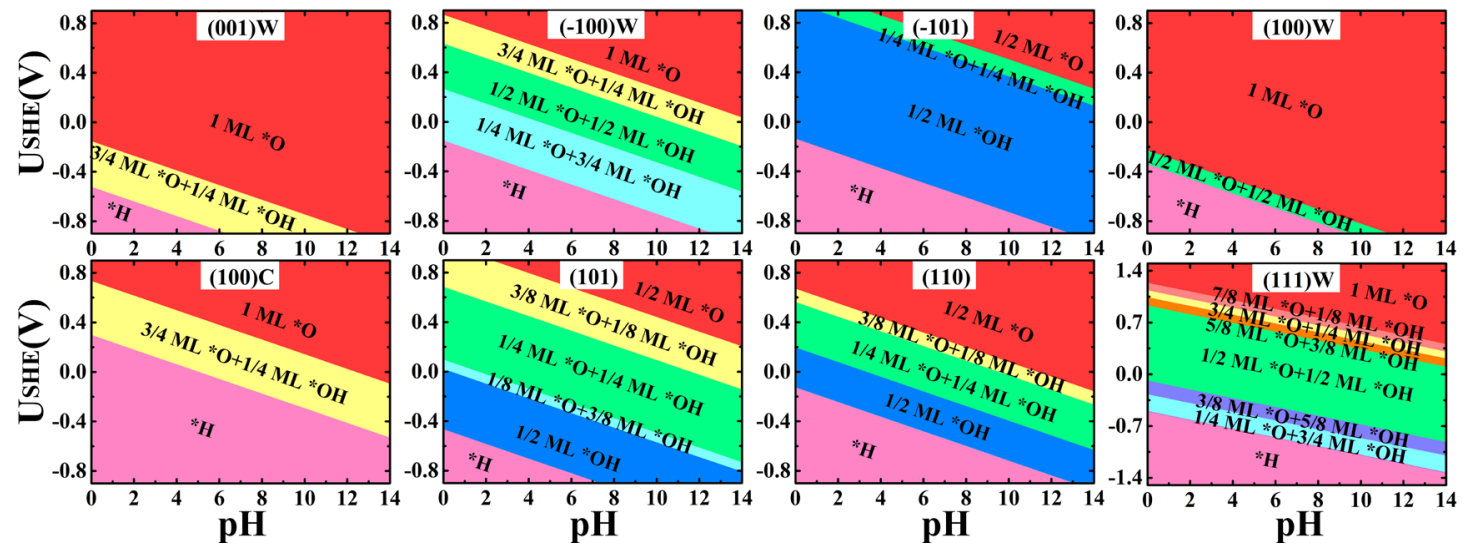

Figure 2. The calculated SPDs of the WC-surfaces studied. For hydrogen evolution, we mainly focus on the stability of surfaces at the $U_{\mathrm{RHE}}=0 \mathrm{~V}$. The raw data are listed in Tables S3 to S7. The results obtained by neglecting spin-polarization and vdW corrections are shown for comparison in Figure S5.

To investigate the role of water effects on the hydrogen evolution, we next turn to the free energy changes $\left(\Delta G_{\mathrm{H}}\right)$ of hydrogen adsorption on the bare, and oxygenated or hydroxylated WC surfaces favored at $0 \mathrm{~V}$ (RHE) potentials. We recall that the latter should correspond to the real surfaces in the experiments. Figure S3 and Table S3 report the calculated $\Delta G_{\mathrm{H}}$ on possible adsorption sites of the bare surfaces. The adsorption site with the lowest $\Delta G_{\mathrm{H}}$ is energetically favored. The analysis is repeated for different hydrogen coverages (Figure S6) and the results displayed in Figure 3a (Table S4). When the absolute value of $\Delta G_{\mathrm{H}}$ is no larger than $0.1 \mathrm{eV}\left(\left|\Delta \mathrm{G}_{\mathrm{H}}\right|<=0.1 \mathrm{eV}\right)$ at the determined $\mathrm{H}$ coverage, this surface is considered to own the excellent HER catalytic performance. As shown in Figure 3a, the $\Delta G_{\mathrm{H}}$ at $5 / 4 \mathrm{H}$ ML of bare $(001) \mathrm{W}$, at $7 / 4 \mathrm{H} \mathrm{ML}$ of bare $(-100) \mathrm{W}$ and at $5 / 8 \mathrm{H} \mathrm{ML}$ and $1 \mathrm{H}$ ML of bare (-101) is 0.08 $\mathrm{eV}, 0.01 \mathrm{eV},-0.10 \mathrm{eV}$ and $-0.04 \mathrm{eV}$, respectively, whereas the determined $\mathrm{H}$ coverages for bare $(001) \mathrm{W}$, $(-100) \mathrm{W}$ and $(-101)$ are 5/4 ML, $2 \mathrm{ML}\left(\Delta G_{\mathrm{H}}=-0.41 \mathrm{eV}\right)$ and $1 \mathrm{ML}$, respectively. Thus, only the bare (001)W and bare (-101) could show high HER activity as only their $\left|\Delta G_{\mathrm{H}}\right|$ at the determined $\mathrm{H}$ coverage is smaller than $0.10 \mathrm{eV}$. The other five bare surfaces will be not good catalytic ones as their larger $\left|\Delta \mathrm{G}_{\mathrm{H}}\right|$ $(>0.10 \mathrm{eV})$.

We next turn to the calculated $\Delta G_{\mathrm{H}}$ for the oxidized or hydroxylated WC surfaces. Figure $\mathbf{S 4}$ reports the $\mathrm{H}$ adsorption geometries for these surfaces. The corresponding $\Delta G_{\mathrm{H}}$ at different $\mathrm{H}$ coverages are 
displayed in Figure 3b. The calculated $\Delta G_{\mathrm{H}}$ for $1 / 4 \mathrm{ML} * \mathrm{O}+3 / 4 \mathrm{ML} * \mathrm{OH}-(-100) \mathrm{W}$ at $1 / 4 \mathrm{H} \mathrm{ML}$ and $1 / 2$ $\mathrm{H} \mathrm{ML}(0.01 \mathrm{eV}$ and 0.10 , respectively) and for $1 / 2 \mathrm{ML} * \mathrm{OH}-(110)$ at $3 / 8 \mathrm{H} \mathrm{ML}(-0.09 \mathrm{eV})$ are located in the gray area $\left(\left|\Delta G_{\mathrm{H}}\right|<=0.10 \mathrm{eV}\right)$, suggesting these systems are the best catalytic surfaces of the seven oxidized or hydroxylated WC surfaces studied. However, the $\left|\Delta G_{\mathrm{H}}\right|$ at their determined $\mathrm{H}$ coverages $(0.01$ $\mathrm{eV}$ on the real (-100)W at $1 / 2 \mathrm{ML}$ and $-0.12 \mathrm{eV}$ on the real (110) at $1 / 2 \mathrm{ML}$ ) indicate only the real (100)W shows the higher HER activity. The remaining five oxidized or hydroxylated surfaces in Figure $3 \mathrm{~b}$, that is $(001) \mathrm{W},(100) \mathrm{W},(111) \mathrm{W},(-101)$ and $(101)$, yield either too larger or too small $\Delta G_{\mathrm{H}}$. These five surfaces are accordingly predicted not to exhibit high HER activities. The real (100)C will still perform as the bare $(100) \mathrm{C}$ surface as they are both free of oxygen and hydroxyl at $U_{\text {RHE }}=0 \mathrm{~V}$, according the SPD. In all, only the real (-100)W surface will show the excellent HER performance.
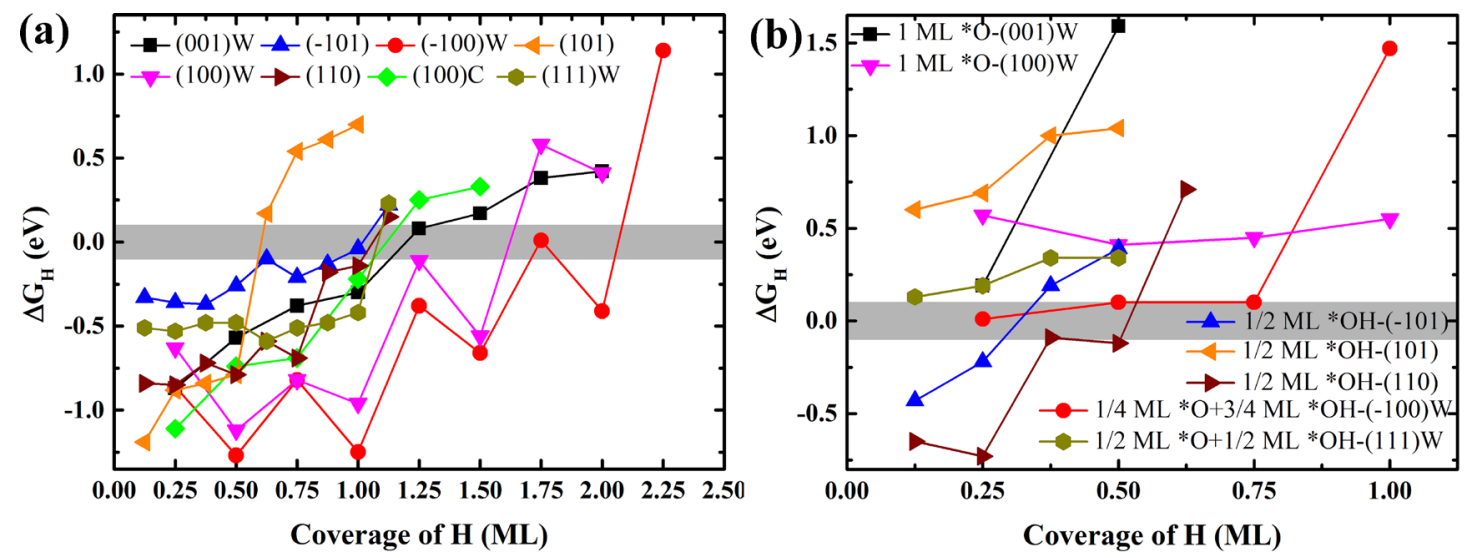

Figure 3. Free-energy changes for adsorbed $\mathrm{H}\left(\Delta G_{\mathrm{H}}\right)$ on the bare (a), and oxidized or hydroxylated WC surfaces favored at $0 \mathrm{~V}$ (RHE) potentials (b) for different $\mathrm{H}$ coverages. The gray area highlights the $\left|\Delta G_{\mathrm{H}}\right|$ $<=0.10 \mathrm{eV}$ domain. The raw data in panels (a) and (b) are listed in Table $\mathbf{S 4}$ and $\mathbf{S 7}$, respectively. The atomic structure for the systems in (a) and (b) are shown in Figure S4 and S6. For comparison, the calculated results with neglect of spin polarization and vdW corrections are shown in Figure S7.

As shown in Figure 3, the hydrogen evolution performance of the bare and oxidized or hydroxylated surfaces can be profoundly different. The $\Delta G_{\mathrm{H}}$ on the bare (-101) surface increases smoothly from $-0.33 \mathrm{eV}$ at $1 / 8 \mathrm{H}$ ML to $-0.26 \mathrm{eV}$ at $1 / 2 \mathrm{H} \mathrm{ML}$, to $0.22 \mathrm{eV}$ at $9 / 8 \mathrm{H}$ ML. Conversely, the $\Delta G_{\mathrm{H}}$ the real (-101) surface increases sharply from $-0.43 \mathrm{eV}$ at $1 / 8 \mathrm{H} \mathrm{ML}$ to $0.39 \mathrm{eV}$ at $1 / 2 \mathrm{H} \mathrm{ML}$. The different trends are due to adsorption of $\mathrm{OH}$ on the real surfaces, which in turn affects the adsorption sites for H. As shown in Figure S6c, the hydrogen atom could adsorb on both the bridge site between the $\mathrm{Mo}$ and the top $\mathrm{C}$-site on the bare (-101). Once the $\mathrm{OH}$ occupies all the bridge sites, the only favorable adsorption site left for $\mathrm{H}$ is on top of a $\mathrm{C}$ atom on real (-101), shown in Figure S4. This originates the larger $\Delta G_{\mathrm{H}}=0.43 \mathrm{eV}$ value on the real (-101) surface at $1 / 2 \mathrm{H}$ ML surface by comparison to the results $(-0.26 \mathrm{eV})$ for the bare $(-101)$ surface at the same $\mathrm{H}$ coverage $(1 / 2 \mathrm{H} \mathrm{ML})$. This result clearly indicates that the adsorption capacity of the real (-101) surface is weaker than that of the bare one. Even if the catalytic sites on the bare and real surface for a given $\mathrm{H}$ coverage are the same (e.g., on top of the $\mathrm{C}$ sites for the bare and real (-101) at $1 \mathrm{H} \mathrm{ML}$ and $1 / 2 \mathrm{H} \mathrm{ML}$, respectively), the hydroxyl on the real surface weakens the hydrogen adsorption ability $(0.39 \mathrm{eV}$ on the real one $\mathrm{vs}-0.10 \mathrm{eV}$ on the bare one), leading to the lower HER activity on the real surface. It can be found that $\Delta G_{\mathrm{H}}$ on $(-100) \mathrm{W},(110)$ and (111)W considering the water effect are closer to $0 \mathrm{eV}$ while comparing to the case of not considering the water effect $\left(\Delta G_{\mathrm{H}}\right.$ at the determined $\mathrm{H}$ coverages are $0.01 \mathrm{eV}$ vs $-0.41 \mathrm{eV},-0.12 \mathrm{eV}$ vs $-0.14 \mathrm{eV}$, and $0.13 \mathrm{eV}$ 
vs $0.23 \mathrm{eV}$, respectively). This indicates the much higher HER activities could be obtained while considering the water effect. In addition, the catalytic sites at the determined $\mathrm{H}$ coverages on the bare and real $(-100) \mathrm{W}$ are also different: bridge of $\mathrm{W}$ and top of the adsorbed $\mathrm{O}$, respectively. The different hydrogen adsorption behaviors on real and bare WC surfaces tell us the importance and necessity of considering water effect through SPD.

\subsubsection{Surface Pourbaix Diagrams and Hydrogen Evolution on Doped Surfaces}

As discussed in the previous section, the HER activities on the real WC surfaces considered are not ideal. Doping is an effective approach to tuning the HER activity by modifying the electronic properties and hydrogen adsorption ability. Thus, in the following we explore the hydrogen evolution on fifteen $\mathrm{V}$, $\mathrm{Mn}$ and $\mathrm{N}$ doped stable surfaces (negative $E_{\mathrm{f}}$ in Figure 1d). The SPDs of the fifteen surfaces are calculated and shown in Figure 4. Table 1 reports the thermodynamically favored terminations for the undoped and doped $\mathrm{WC}$ at $\mathrm{U}_{\mathrm{RHE}}=0 \mathrm{eV}$. The atomic structure of these systems is shown in Figure $\mathbf{S 8}$. Comparison of the results between the doped and undoped surfaces reveals the following trends. In general, the total coverage of $\mathrm{O}$ and $\mathrm{OH}$ is unchanged for each $\mathrm{V}$, or $\mathrm{N}$ doped surface, but the respective coverage of $\mathrm{O}$ or $\mathrm{OH}$ may be different. For example, the real surfaces of the bare and V-doped (-100)W are covered by 1/4 ML O and 3/4 ML OH, and $1 \mathrm{ML} \mathrm{OH} \mathrm{(1} \mathrm{ML} \mathrm{in} \mathrm{total),} \mathrm{respectively.} \mathrm{However,} \mathrm{the} \mathrm{total}$ coverage of $\mathrm{O}$ and $\mathrm{OH}$ decreases for two Mn doped surfaces (110), (111)W, and remains unchanged for the $(-100) \mathrm{W},(100 \mathrm{~W})$ surfaces. In the following we analyze the interplay between dopant and detailed level of oxidation of hydroxylation (adsorbed $* \mathrm{O}$ and $* \mathrm{OH}$ ) for the emerging HER properties of the doped surfaces. 

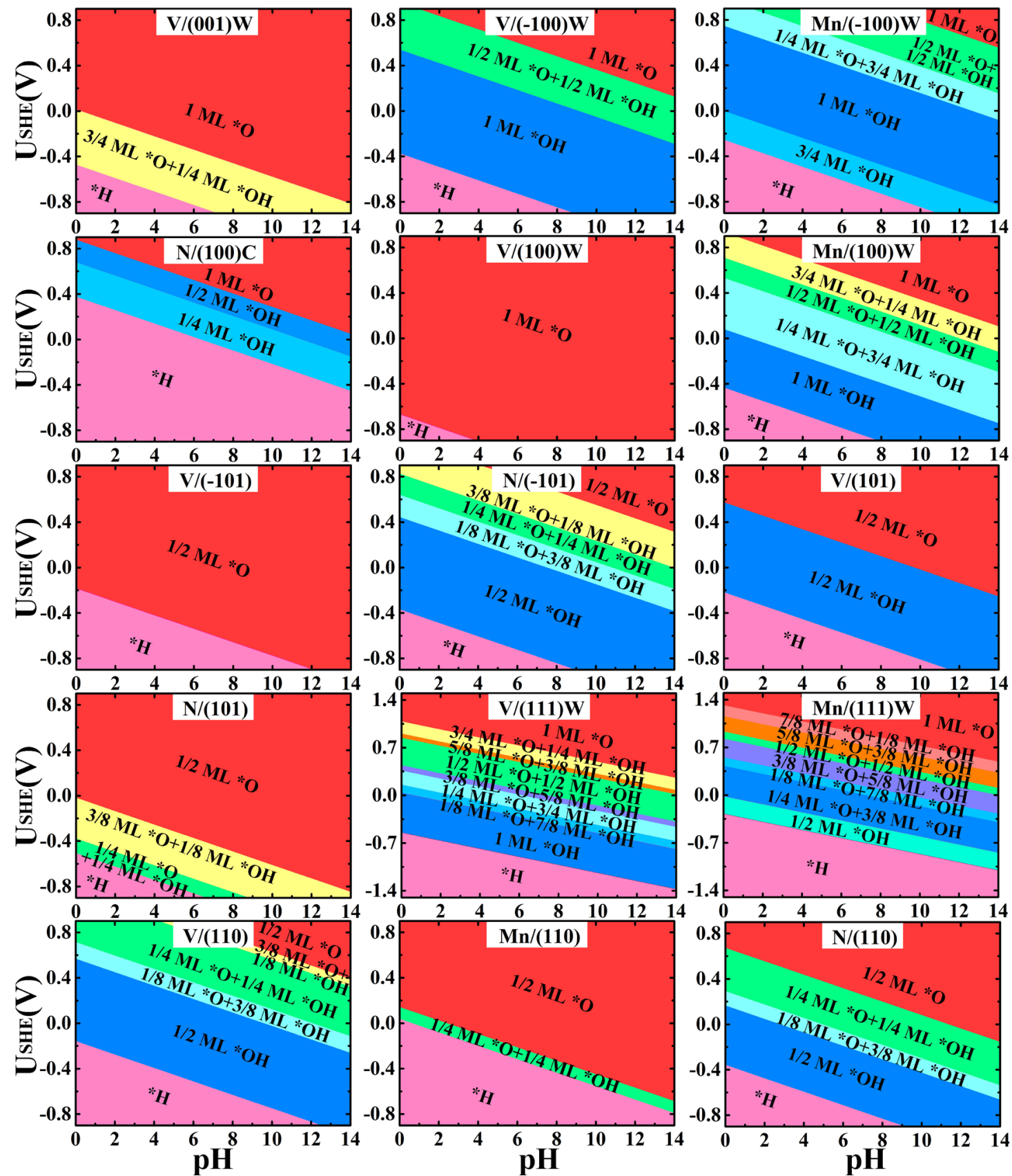

Figure 4. The surface Pourbaix diagrams of the doped-WC surfaces. The symbol "*H" means the doped surface is free of $* \mathrm{O}$ and $* \mathrm{OH}$ and tends to adsorb $\mathrm{H}$. The raw data are listed in Table S3 $\sim \mathbf{S 7}$.

Based on the obtained real doped WC surfaces in Table $\mathbf{1}, \Delta G_{\mathrm{H}}$ at different $\mathrm{H}$ coverages are calculated and shown in Figure 5. In total, there are six different doped surfaces with $\Delta G_{\mathrm{H}}$ located in the grey area $(-0.10 \sim 0.10 \mathrm{eV})$ which may show possible HER activity. These are three V-doped $(\mathrm{V} /(001) \mathrm{W}$, $\mathrm{V} /(101), \mathrm{V} /(111) \mathrm{W})$, two Mn-doped (Mn/(110), Mn/(111)W) and one N-doped (N/(101)) surface. The specific $\Delta G_{\mathrm{H}}$ values of in grey-area are: $0.03 \mathrm{eV}$ at $1 / 4 \mathrm{H} \mathrm{ML} \mathrm{V/(001)W,}-0.04 \mathrm{eV}$ at 3/8 $\mathrm{H}$ ML and -0.03 $\mathrm{eV}$ at $1 / 2 \mathrm{H} \mathrm{ML}$ on $\mathrm{V} /(101),-0.01 \mathrm{eV}$ at $1 / 2 \mathrm{H} \mathrm{ML}$ and $-0.10 \mathrm{eV}$ at $3 / 8 \mathrm{H} \mathrm{ML}$ and $0.04 \mathrm{eV}$ at $1 / 2 \mathrm{H} \mathrm{ML}$ on $\mathrm{V} /(111) \mathrm{W},-0.10 \mathrm{eV}$ at 5/8 and 3/4 $\mathrm{H} \mathrm{ML}$ on $\mathrm{Mn} /(110), 0.06 \mathrm{eV}$ at $1 / 4 \mathrm{H} \mathrm{ML}$ on $\mathrm{Mn} /(111) \mathrm{W}$, and 0.06 $\mathrm{eV}$ at $1 / 8 \mathrm{H} \mathrm{ML}$ and $0.08 \mathrm{eV}$ at $1 / 4 \mathrm{H} \mathrm{ML}$ on $\mathrm{N} /(101)$. While considering the $\Delta G_{\mathrm{H}}$ at their determined $\mathrm{H}$ coverages, only three $\mathrm{V}$ doped and one $\mathrm{N}$ doped surfaces will show suitable values of $\Delta G_{\mathrm{H}}$ : $\mathrm{V} /(001) \mathrm{W}$ 
(0.03 eV on top of $\mathrm{O}$ atom at $1 / 4 \mathrm{H} \mathrm{ML}), \mathrm{V} /(101)(-0.03 \mathrm{eV}$ on top of $\mathrm{C}$ atom at $1 / 2 \mathrm{H} \mathrm{ML})$, $\mathrm{V} /(111) \mathrm{W}(0.04 \mathrm{eV}$ on top of $\mathrm{C}$ atom at $1 / 2 \mathrm{H} \mathrm{ML})$, and $\mathrm{N} /(101)(0.08 \mathrm{eV}$ on top of $\mathrm{N}$ atom at $1 / 4 \mathrm{H} \mathrm{ML})$. One interesting finding is that, the adsorbed $\mathrm{O}$ atom can also act as an superior active catalytic site, e.g., real $\mathrm{V} /(001) \mathrm{W}$ is covered by $1 \mathrm{ML} * \mathrm{O}$ and the adsorbed $\mathrm{O}$ atom is the only adsorption site for $\mathrm{H}$ atom, as shown in Figure S8, and the $\Delta G_{\mathrm{H}}$ is $0.03 \mathrm{eV}$. In all, only the V doped (001)W, (101) and (111)W, and the $\mathrm{N}$ doped (101) could show excellent HER activities according to our DFT results.

Table 1. Compilation of the thermodynamically favored terminations for the real undoped and doped WC surfaces in water at $\mathrm{U}_{\mathrm{RHE}}=0 \mathrm{eV}$. The "per", V, Mn, and N labels denote the pristine, V-doped, Mndoped, and N-doped WC surfaces, respectively.

\begin{tabular}{|c|c|c|c|c|c|c|c|c|}
\hline Surfaces & $(001) \mathrm{W}$ & $(-100) \mathrm{W}$ & $(100) \mathrm{W}$ & $(-101)$ & (101) & $(100) \mathrm{C}$ & (110) & (111)W \\
\hline \multirow[t]{2}{*}{ Per } & $1 \mathrm{ML} * \mathrm{O}$ & $1 / 4 \mathrm{ML} * \mathrm{O}+3 / 4$ & $1 \mathrm{ML} * \mathrm{O}$ & $1 / 2 \mathrm{ML}$ & $1 / 2 \mathrm{ML}$ & Bare & $1 / 2 \mathrm{ML}$ & $1 / 2 \mathrm{ML} * \mathrm{O}+1 / 2$ \\
\hline & & $\mathrm{ML} * \mathrm{OH}$ & & $* \mathrm{OH}$ & $* \mathrm{OH}$ & & $* \mathrm{OH}$ & $\mathrm{ML} * \mathrm{OH}$ \\
\hline \multirow[t]{2}{*}{$\mathrm{V}$} & $1 \mathrm{ML} * \mathrm{O}$ & $1 \mathrm{ML} * \mathrm{OH}$ & $1 \mathrm{ML} * \mathrm{O}$ & $1 / 2 \mathrm{ML}$ & $1 / 2 \mathrm{ML}$ & - & $1 / 2 \mathrm{ML}$ & $1 \mathrm{ML} * \mathrm{OH}$ \\
\hline & & & & $* \mathrm{O}$ & $* \mathrm{OH}$ & & $* \mathrm{OH}$ & \\
\hline \multirow[t]{2}{*}{$\mathrm{Mn}$} & - & $1 \mathrm{ML} * \mathrm{OH}$ & $1 \mathrm{ML}$ & - & - & - & Bare & $1 / 4 \mathrm{ML} * \mathrm{O}+3 / 8$ \\
\hline & & & $* \mathrm{OH}$ & & & & & $\mathrm{ML} * \mathrm{OH}$ \\
\hline \multirow[t]{2}{*}{$\mathrm{N}$} & - & - & - & $1 / 2 \mathrm{ML}$ & $1 / 2 \mathrm{ML}$ & Bare & $1 / 2 \mathrm{ML}$ & - \\
\hline & & & & $* \mathrm{OH}$ & $* \mathrm{O}$ & & $* \mathrm{OH}$ & \\
\hline
\end{tabular}

The values of $\Delta G_{\mathrm{H}}$ on the four doped surfaces turns out to be more favorable for HER by comparison to the results for the corresponding undoped ones. The $\Delta G_{\mathrm{H}}$ at determined $\mathrm{H}$ coverages on the real $(001) \mathrm{W}$, real (101), real (111)W, and the (100)C (see Figure 3b) are $0.19 \mathrm{eV}$ on top of O atom at 1/4 H ML, 0.60 $\mathrm{eV}$ on top of $\mathrm{C}$ atom at $1 / 8 \mathrm{H} \mathrm{ML}, 0.13 \mathrm{eV}$ on top of $\mathrm{C}$ atom at $1 / 8 \mathrm{H} \mathrm{ML}$, and $-0.22 \mathrm{eV}$ on top of $\mathrm{C}$ atom at $1 \mathrm{H} \mathrm{ML}$, respectively. It is worth noting that, based on the calculated $\Delta G_{\mathrm{H}}$ values, the HER activity of (001)W, (101), (111)W, and (100)C result improved by V or $\mathrm{N}$ doping. Changes in $\Delta G_{\mathrm{H}}$ on the doped and undoped surfaces may be due to four factors: the dopant atoms, the adsorption conditions of $\mathrm{O}$ or $\mathrm{OH}$, the sites of $\mathrm{H}$ adsorption, and the determined $\mathrm{H}$ coverage. We take the $\mathrm{N} /(100) \mathrm{C}$ and $(100) \mathrm{C}$ as an example for discussing these points. Both of the two real surfaces are free of $\mathrm{O}$ and $\mathrm{OH}$, thus the enhanced HER activity of $\mathrm{N} /(100) \mathrm{C}$ is necessarily induced by the other three factors: the $\mathrm{N}$ dopant, the different sites of $\mathrm{H}$ adsorption (top of $\mathrm{N}$ vs top of $\mathrm{C}$ atom), different $\mathrm{H}$ coverages (1/4 H ML vs $1 \mathrm{H} \mathrm{ML}$ ). The $\mathrm{N}$ dopant in (100)C will make the $\mathrm{H}$ adsorption ability much weaker, which could be concluded by the $\Delta G_{\mathrm{H}}$ at the same $\mathrm{H}$ coverage : $0.13 \mathrm{eV}$ vs $-1.11 \mathrm{eV}$ at $1 / 4 \mathrm{H}$ ML. A similar analysis could be also applied to the other three $\mathrm{V}$ doped surfaces. For example, the $\mathrm{V}$ doping could increase the $\mathrm{H}$ adsorption ability of of real (100): the $\Delta G_{\mathrm{H}}$ on top of $\mathrm{C}$ of the real (101) and real $\mathrm{V} /(101)$ are $0.60 \mathrm{eV}$ and $-0.47 \mathrm{eV}$ at same $\mathrm{H}$ coverage $(1 / 8 \mathrm{H} \mathrm{ML})$, respectively. However, the $\Delta G_{\mathrm{H}}$ on the former and latter surface at determined $\mathrm{H}$ coverage is $-0.03(1 / 2 \mathrm{H} \mathrm{ML})$ and $0.60 \mathrm{eV}(1 / 8 \mathrm{H} \mathrm{ML})$, respectively. 


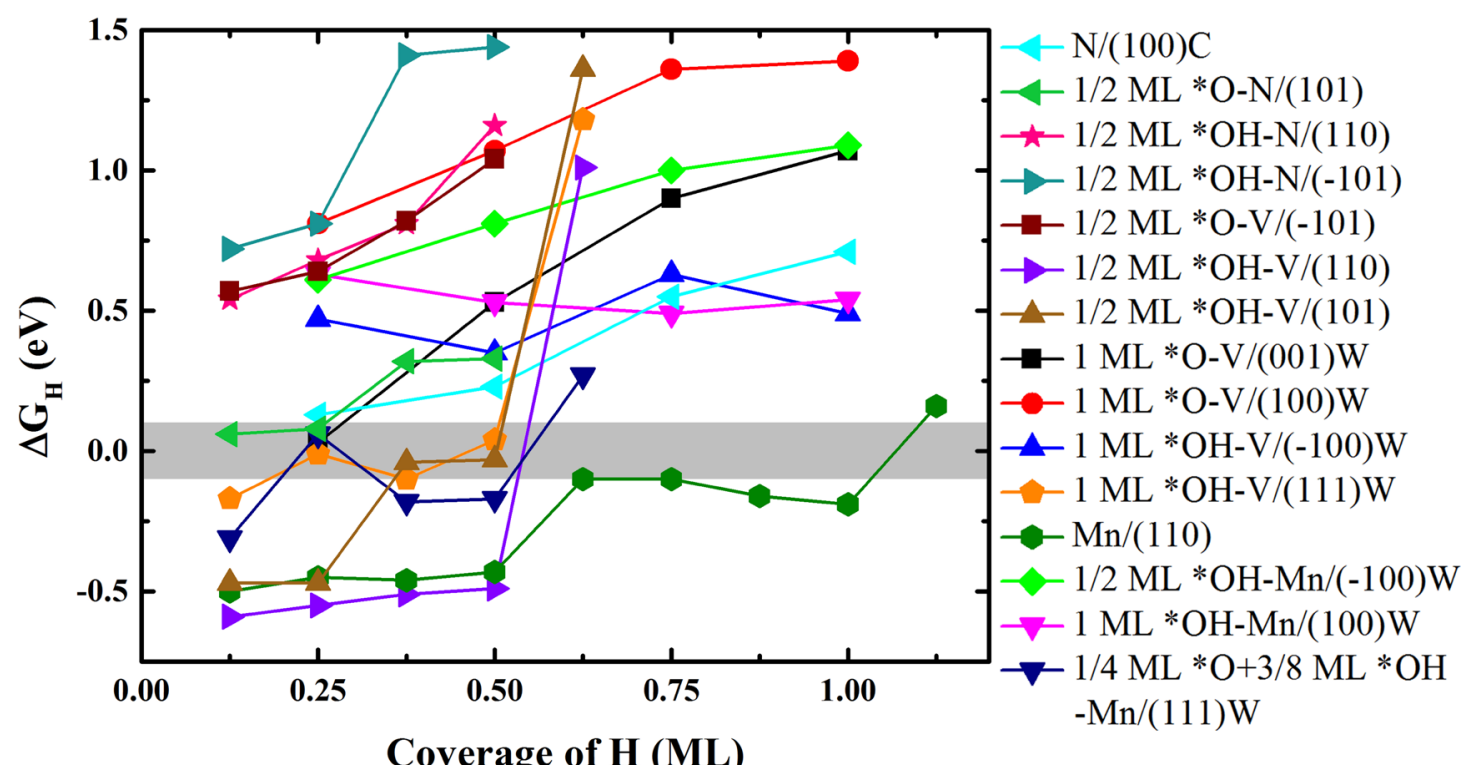

Figure 5. Adsorption free-energy changes $\left(\Delta G_{\mathrm{H}}\right)$ for adsorbed $\mathrm{H}$ on doped WC surfaces at different $\mathrm{H}$ coverage $(1 / 8 \sim 1 \mathrm{ML})$. The gray area highlights the $\left|\Delta \mathrm{G}_{\mathrm{H}}\right|<=0.10 \mathrm{eV}$ domain of. The raw data are listed in Table $\mathbf{S 7 .}$

There are two further points that needs to be stressed. Firstly, the HER activity of WC surfaces may increase or decrease (e.g., N/(-101), V/(110), and $\mathrm{Mn} /(110)$ ) by $\mathrm{Mn}, \mathrm{V}$, and $\mathrm{N}$ doping. Secondly, the other doped surfaces with $\Delta G_{\mathrm{H}}$ out of the gray area $\left(\left|\Delta \mathrm{G}_{\mathrm{H}}\right|>0.10 \mathrm{eV}\right)$ in Figure 5 would not display excellent HER activities, we will not discuss in this part.

\subsection{Exchange Current Density}

In order to compare the HER activity of different surfaces, the exchange current densities of the undoped and doped WC surfaces are calculated (Figure 6). Here, the V, Mn and N doped surfaces are the real doped ones, and the "* $\mathrm{O}$ and * $\mathrm{OH}$ " surfaces are the real undoped ones. This analysis clearly shows that the relationship between the exchange current density (ECD) and hydrogen adsorption ability $\left(\Delta G_{\mathrm{H}}\right.$ at the determined $\mathrm{H}$ coverage) follows a volcano shape. All the surfaces located at the gray part in Figure 6 show a considerable ECD, larger than $0.1 \mathrm{~mA} / \mathrm{cm}^{2}$. The undoped surfaces are discussed firstly. There are two real surfaces with ECDs larger than $0.1 \mathrm{~mA} / \mathrm{cm}^{2},(-100) \mathrm{W}$ with $3.908 \mathrm{~mA} / \mathrm{cm}^{2}$ and (111)W with $0.133 \mathrm{~mA} / \mathrm{cm}^{2}$. The other six real undoped surfaces, including (001)W, (110), (-101), (100)C, (100)W, and (101), yield ECDs lower than $0.1 \mathrm{~mA} / \mathrm{cm}^{2}$. According to the previous theoretical and experimental results, ${ }^{25-28}$ the (100), (101), and (001) are the most stable surfaces of WC. In our DFT calculations, the value of ECD on $(100) \mathrm{C},(100) \mathrm{W},(101)$ and $(001) \mathrm{W}$ is $2.040 \times 10^{-3} \mathrm{~mA} / \mathrm{cm}^{2}, 1.163 \times 10^{-}$ ${ }^{8} \mathrm{~mA} / \mathrm{cm}^{2}, 2.743 \times 10^{-9} \mathrm{~mA} / \mathrm{cm}^{2}, 2.949 \times 10^{-2} \mathrm{~mA} / \mathrm{cm}^{2}$, respectively. The calculated values for the former three and last one are smaller and larger than the experimental value $\left(\sim 2.5 \times 10^{-3} \mathrm{~mA} / \mathrm{cm}^{2}\right) .{ }^{25}$ Thus, the real (001)W dominate the HER performance of WC in experiments. In addition, although (-100)W and (111)W yield even larger ECDs, their contribution to experimental values of ECD will be much reduced as their small ratio to exposed WC surfaces in experiment. Thus, Our DFT calculated values of exchange currents are in accord with the experimental value $\left(2.5 \times 10-3 \mathrm{~mA} / \mathrm{cm}^{2}\right)$ of $\mathrm{WC}$ in previous work, ${ }^{25-28}$ indicating the reliability of our DFT results. For comparison, the ECDs of bare undoped WC (black squares) surfaces are also given in the plot. It could be easily seen that the corresponding values between the bare and real ones are different, e.g., $1.275 \mathrm{~mA} / \mathrm{cm}^{2}$ on bare $(-101) \mathrm{vs} 3.051 \times 10^{-3} \mathrm{~mA} / \mathrm{cm}^{2}$ on real (- 
101) (covered by $1 / 2 \mathrm{ML} \mathrm{OH}$ ). Moreover, the exchange current densities of these three surfaces, (-100)W, (110) and (111)W considering the water effect could be greatly increased while comparing to the case without considering the water effect $\left(3.908 \mathrm{~mA} / \mathrm{cm}^{2}\right.$ vs $1.368 \times 10^{-6} \mathrm{~mA} / \mathrm{cm}^{2}, 5.460 \times 10^{-2} \mathrm{~mA} / \mathrm{cm}^{2}$ vs $2.543 \times 10^{-2} \mathrm{~mA} / \mathrm{cm}^{2}$, and $0.133 \mathrm{~mA} / \mathrm{cm}^{2}$ vs $2.854 \times 10^{-3} \mathrm{~mA} / \mathrm{cm}^{2}$, respectively), which is consist with our discussion about the adsorption free-energy changes in Figure 3. These results reiterate the importance of considering the water effect in exploring the surfaces of HER electrocatalysts.

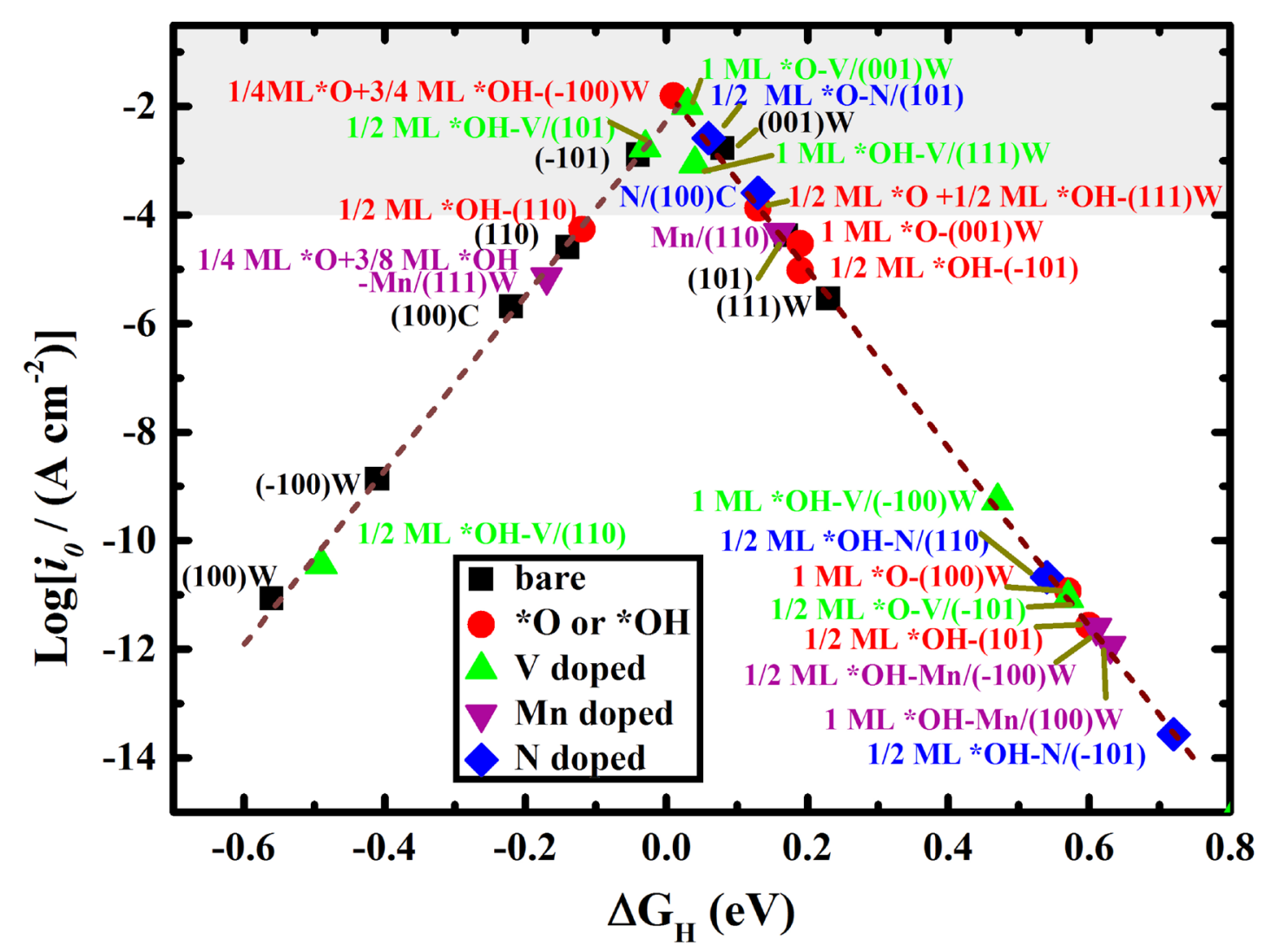

Figure 6. The exchange current densities as a function of the hydrogen adsorption free energy change $\left(\Delta G_{\mathrm{H}}\right)$ at the determined $\mathrm{H}$ coverage. The gray area highlights the domain of $i_{0}>=10^{-4} \mathrm{~A} / \mathrm{cm}^{2}$.

The results in Figure 6 indicate that V, Mn and N doping can significantly increase the ECDs of some WC surfaces. In some cases, the calculated ECDs for doped surface are larger than for the undoped ones. The V atom emerges as the best dopant of WC for HER, as the ECDs of the V/(001)W, V/(101) and $\mathrm{V} /(111) \mathrm{W}$ reach the largest values, $10.555 \mathrm{~mA} / \mathrm{cm}^{2}, 1.730 \mathrm{~mA} / \mathrm{cm}^{2}$ and $0.876 \mathrm{~mA} / \mathrm{cm}^{2}$, respectively. $\mathrm{N}$-doping can also raise the ECDs of two WC surfaces to values $>0.1 \mathrm{~mA} / \mathrm{cm}^{2}: 0.258 \mathrm{~mA} / \mathrm{cm}^{2}$ on $\mathrm{N} /(100) \mathrm{C}$, and $0.636 \mathrm{~mA} / \mathrm{cm}^{2}$ on $\mathrm{N} /(101)$, respectively. The three $\mathrm{V}$ doped and two $\mathrm{N}$ doped WC surfaces show higher HER activities than the corresponding undoped ones. The ECD for the V/(001)W and $\mathrm{V} /(101)$ are even comparable with commercial $20 \% \mathrm{Pt} / \mathrm{C}\left(2.868 \mathrm{~mA} / \mathrm{cm}^{2}\right),{ }^{28,44,48}$ with several others in the white part $\left(<0.1 \mathrm{~mA} / \mathrm{cm}^{2}\right)$ of Figure 6. The improved ECDs by doping are also in accord with the discussion of $\Delta G_{\mathrm{H}}$ in last two sections. Previous work has observed that $\mathrm{N}$ doping can increase the HER activity of (100)C. . $^{38}$

However, doping may also quench HER activity for some surfaces, e.g., the real $(-101)\left(3.051 \times 10^{-}\right.$ $\left.{ }^{3} \mathrm{~mA} / \mathrm{cm}^{2}, 1 / 2 \mathrm{ML} \mathrm{OH}\right)$ and the real $\mathrm{N} /(-101)\left(2.715 \times 10^{-11} \mathrm{~mA} / \mathrm{cm}^{2}, 1 / 2 \mathrm{ML} \mathrm{OH}\right)$, the real (110) $\left(5.460 \times 10^{-2} \mathrm{~mA} / \mathrm{cm}^{2}, 1 / 2 \mathrm{ML} \mathrm{OH}\right)$ and the real $\mathrm{N} /(110)\left(2.128 \times 10^{-8} \mathrm{~mA} / \mathrm{cm}^{2}, 1 / 2 \mathrm{ML} \mathrm{OH}\right)$, the real $(110)$ 
$\left(5.460 \times 10^{-2} \mathrm{~mA} / \mathrm{cm}^{2}, 1 / 2 \mathrm{ML} \mathrm{OH}\right)$ and the real $\mathrm{V} /(110)\left(3.640 \times 10^{-8} \mathrm{~mA} / \mathrm{cm}^{2}, 1 / 2 \mathrm{ML} \mathrm{OH}\right)$. Thus, it is vital to know what kind of dopants could increase the HER activity on a certain surface.

\subsection{Relationship between Electronic Properties and Hydrogen Adsorption Ability}

In order to understand the inherent mechanisms of the water effect and doping on the WC surfaces, it is necessary to explore how the electronic properties affect the hydrogen adsorption ability $\left(\Delta G_{\mathrm{H}}\right)$. Figure 7 reports the calculated electronic properties for several selected surface, including the density of state, $p$-band center $\left(E_{p}\right)$ of the nonmetal atoms in the top layer, and $d$-band center $\left(E_{d}\right)$. According to the $d$-band and $p$-band theory, the downshift of the $E_{d}$ or $E_{p}$ can weaken the adsorption ability of the adsorbate, or hydrogen atom in this work. ${ }^{55-59}$ In the following, we analyze separately the role of the water effect, $\mathrm{V}$ doping, and $\mathrm{N}$ doping for the surface electronic properties.

The hydrogen adsorption ability is weakened by adsorption of $* \mathrm{O}$ or $* \mathrm{OH}$ on the WC surfaces. Similar conclusion were also drawn about molybdenum carbides in previous work. ${ }^{36}$ This trend of hydrogen adsorption ability could be attributed to the down shift of the $d$-band center of the W atom due to oxygen adsorption. The down shift of the $d$-band center on a given surfaces could be clearly seen from the corresponding different values for the bare $(001) \mathrm{W}$ and $1 \mathrm{ML} * \mathrm{O}-(001) \mathrm{W}(-6.36 \mathrm{eV}$ vs $-8.38 \mathrm{eV})$, bare (100)W and $1 \mathrm{ML} * \mathrm{O}-(100) \mathrm{W}(-6.58 \mathrm{eV}$ vs $-7.40 \mathrm{eV})$, bare (101) and 1/2 ML*OH-(101) $(-5.12 \mathrm{eV}$ vs $-5.17 \mathrm{eV}$ ) in the two bottom panels of Figure $7 \mathrm{a}, 7 \mathrm{~b}$ and $7 \mathrm{c}$, respectively. The corresponding $\Delta G_{\mathrm{H}}$ shifts are $-0.87 \mathrm{eV}$ at the FCC site of $\mathrm{W}$ atom on bare $(001) \mathrm{W}$ vs $0.19 \mathrm{eV}$ at the top site of oxygen atom on $1 \mathrm{ML} * \mathrm{O}-(001) \mathrm{W},-0.63 \mathrm{eV}$ at the bridge site of $\mathrm{W}$ atom on bare $(100) \mathrm{W}$ vs $0.57 \mathrm{eV}$ at the top site of $\mathrm{W}$ atom on $1 \mathrm{ML} * \mathrm{O}-(100) \mathrm{W}$, and $-1.19 \mathrm{eV}$ at the bridge site of $\mathrm{W}$ atom on bare (101) vs $0.60 \mathrm{eV}$ at the top site of carbon atom on $1 / 2 \mathrm{ML} * \mathrm{OH}-(101)$. Our combined results for the shift of $d$-band center of the $\mathrm{W}$ atom and the $\Delta G_{\mathrm{H}}$ agree well with the $d$-band center theory for each facet.

One important aspect that should be noted is the different hydrogen adsorption sites for $\Delta G_{\mathrm{H}}$ on the bare and related oxidized or hydroxylated surfaces. In general, electronic charge is transferred from the $\mathrm{W}$ atom to the adsorbed $\mathrm{O}$ or $\mathrm{OH}$ once the surface is oxidized or hydroxylated, making the $d$-band less occupied and downshifting its center. This will lead to weaker adsorption ability of $\mathrm{H}$ atom on the oxidized or hydroxylated surfaces. 

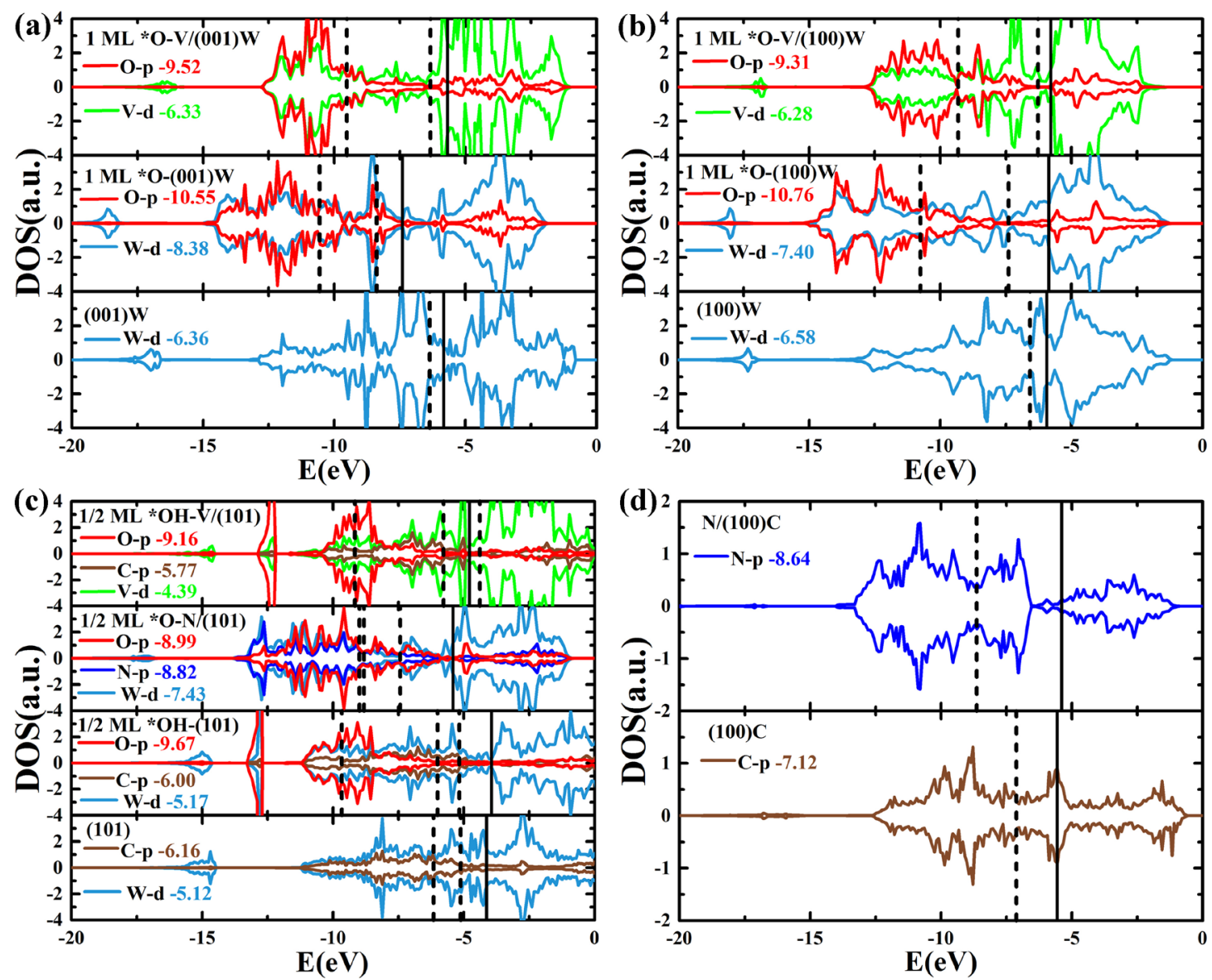

Figure 7. The calculated Density of States (DOS) of (a) (001)W, (b) (100)W, (c) (101), (d) (100)C. The solid vertical lines mark the position of the Fermi level, and the vacuum level is set to $0 \mathrm{eV}$. The dashed lines mark the band center, whose value also reported (in $\mathrm{eV}$ ).

The simulations reveal that the $d$-band center of the $\mathrm{V}$ atom will be higher than that of the $\mathrm{W}$ atom, leading to stronger hydrogen adsorption ability (more negative $\Delta G_{\mathrm{H}}$ ), as shown in Figure 7 and Table 2. If the adsorption site is on top of a nonmetal atom on the undoped and $\mathrm{V}$ doped surfaces, the $\Delta G_{\mathrm{H}}$ also follows the $p$-band center rules just as the $d$-band center for a given facet: the less negative the $p$-band center, the stronger the hydrogen adsorption ability for the site. This can be concluded from the $\mathrm{V}$ doping cases of the real doped (001)W, (100)W and (101) surfaces: a) the adsorption site on the first, and second, and third one is top of oxygen, oxygen, and carbon atom, respectively, regardless of the V doping. Here, we should keep in mind the $\Delta G_{\mathrm{H}}(\mathrm{O})$ (hydrogen on top of oxygen atom) is the second most favorable site on real $(100) \mathrm{W}$, and the value is $0.87 \mathrm{eV}$, see Table 2; b) The $\mathrm{V}$ doping will make the $p$-band center of the oxygen atom on $(001) \mathrm{W}$, oxygen atom on $(100) \mathrm{W}$, and carbon atom of (101) increase from -10.55 $\mathrm{eV},-10.76 \mathrm{eV}$ and $-6.00 \mathrm{eV}$ to $-9.52 \mathrm{eV},-9.31 \mathrm{eV}$ and $-5.77 \mathrm{eV}$, respectively, whereas make the corresponding $\Delta G_{\mathrm{H}}$ decrease from $0.19 \mathrm{eV}, 0.87 \mathrm{eV}$ and $0.60 \mathrm{eV}$ to $0.03 \mathrm{eV}, 0.81 \mathrm{eV}$ and $-0.47 \mathrm{eV}$, respectively. In sum, $\mathrm{V}$ doping weakens the hydrogen adsorption ability, both the $d$-band center and $p$ band center theory are suitable for one given surface.

Table 2. The favored hydrogen adsorption sites, $\Delta G_{\mathrm{H}}$, and corresponding band centers (adsorption site and metal atoms) for the surfaces in Figure 7. The most favorable adsorption ones are in bold, according 
to our DFT results. B, T, and T* represent the bridge, top, and inclined top site, respectively, see Figure S3.

\begin{tabular}{|c|c|c|c|c|}
\hline & \multicolumn{3}{|c|}{ band center $(\mathrm{eV})$} & \multirow{2}{*}{$\Delta G_{\mathrm{H}}(\mathrm{eV})$} \\
\hline & site & site atom & metal atom & \\
\hline $1 \mathrm{ML} * \mathrm{O}-\mathrm{V} /(001) \mathrm{W}$ & $\mathrm{O}-\mathrm{T}$ & $-9.52(\mathrm{O})$ & $-6.33(\mathrm{~V})$ & 0.03 \\
\hline $1 \mathrm{ML} * \mathrm{O}-(001) \mathrm{W}$ & $\mathrm{O}-\mathrm{T}$ & $-10.55(\mathrm{O})$ & $-8.38(W)$ & 0.19 \\
\hline$(001) \mathrm{W}$ & W-FCC & $-6.36(W)$ & $-6.36(W)$ & -0.87 \\
\hline $1 \mathrm{ML} * \mathrm{O}-\mathrm{V} /(100) \mathrm{W}$ & $\mathrm{O}-\mathrm{T}$ & $-9.31(\mathrm{O})$ & $-6.28(\mathrm{~V})$ & 0.81 \\
\hline \multirow{2}{*}{$1 \mathrm{ML} * \mathrm{O}-(100) \mathrm{W}$} & W-T & $-7.40(\mathrm{~W})$ & \multirow{2}{*}{$-7.40(\mathrm{~W})$} & 0.66 \\
\hline & $\mathrm{O}-\mathrm{T}$ & $-10.76(\mathrm{O})$ & & 0.87 \\
\hline$(100) \mathrm{W}$ & W-B1 & $-6.58(W)$ & $-6.58(W)$ & -0.63 \\
\hline $1 / 2 \mathrm{ML} * \mathrm{OH}-\mathrm{V} /(101)$ & $\mathrm{C}-\mathrm{T}$ & $-5.77(\mathrm{C})$ & $-4.39(\mathrm{~V})$ & -0.47 \\
\hline \multirow{2}{*}{$1 / 2 \mathrm{ML} * \mathrm{O}-\mathrm{N} /(101)$} & $\mathrm{O}-\mathrm{T}^{*}$ & $-8.99(\mathrm{O})$ & \multirow{2}{*}{$-7.43(\mathrm{~W})$} & 0.06 \\
\hline & N-T & $-8.82(\mathrm{~N})$ & & 0.90 \\
\hline $1 / 2 \mathrm{ML} * \mathrm{OH}-(101)$ & $\mathrm{C}-\mathrm{T}$ & $-6.00(\mathrm{C})$ & $-5.17(\mathrm{~W})$ & 0.60 \\
\hline$(101)$ & W-B & $-5.12(\mathrm{~W})$ & $-5.12(\mathrm{~W})$ & -1.19 \\
\hline $\mathrm{N} /(100) \mathrm{C}$ & N-T & $-8.64(\mathrm{~N})$ & - & 0.13 \\
\hline$(100) \mathrm{C}$ & C-T & $-7.12(\mathrm{C})$ & - & -1.11 \\
\hline
\end{tabular}

Analysis of the results for the N-doped surfaces reveals a more complex scenario. On the one hand, the $p$-band center theory is expected to hold when applied to the (100)C and N/(100)C in Figure 7d. The $p$-band center of the $\mathrm{N}$ atom $(-8.64 \mathrm{eV})$ for $\mathrm{N} /(100) \mathrm{C}$ is $1.52 \mathrm{eV}$ smaller than that of $\mathrm{C}$ atom $(-7.12 \mathrm{eV})$ in (100)C. The calculated $\Delta G_{\mathrm{H}}$ is accordingly increased from $-1.11 \mathrm{eV}$ to $0.13 \mathrm{eV}$. In other words, the $\mathrm{N}$ doping can decrease the $p$-band center of (100)C, and weaken the hydrogen adsorption ability. On the other hand, the $p$-band center theory seems inapplicable to the real (101) and real $\mathrm{N} /(101)$, as the hydrogen adsorption ability increases from the former $(0.60 \mathrm{eV}$ on top of $\mathrm{C}$ atom $)$ to the latter one $(0.06$ $\mathrm{eV}$ on inclined top of $\mathrm{O}$ atom), whereas the $p$-band center of the adsorption site decrease from $-6.00 \mathrm{eV}$ to $-8.99 \mathrm{eV})$. The failure of $p$-band center theory to real (101) and real $\mathrm{N} /(101)$ could attribute to the different kinds of adsorption sites and the related bonding behavior. In Figure S9, it could be clearly shown that the $s$ orbital of $\mathrm{H}$ atom mainly couple with the $p_{\mathrm{z}}$ orbital of $\mathrm{C}$ atom of real (101) and $\mathrm{N}$ atom of real $\mathrm{N} /(101)$, and $p_{\mathrm{x}}$ and $p_{\mathrm{z}}$ orbital of $\mathrm{O}$ atom of real $\mathrm{N} /(101)$, respectively. This indicates that different adsorption sites will lead to different bonding behavior. The $p$-band theory only works while considering the same adsorption site, as the similar bonding behavior, such as $\mathrm{H}$ adsorbed at top site of $\mathrm{C}$ atoms in real (101) and $\mathrm{N}$ atoms in real $\mathrm{N} /(101)$, and their PDOS indicate that $s$ orbital of $\mathrm{H}$ atom mainly couple with the $p_{\mathrm{z}}$ orbital of $\mathrm{C}$ and $\mathrm{N}$ atoms, respectively. The $\Delta G_{\mathrm{H}}$ on top of $\mathrm{C}$ of real (101) and $\mathrm{N}$ of real $\mathrm{N} /(101)$ is $0.60 \mathrm{eV}$ and $0.90 \mathrm{eV}$, respectively, and the corresponding $E_{\mathrm{p}}$ of $\mathrm{C}$ and $\mathrm{N}$ atoms is $-6.00 \mathrm{eV}$ and -8.82 $\mathrm{eV}$, respectively. One more thing is that the discussions of the band center theory here are only limited to one facet. It will be not powerful when referring different facets, e.g., the bare (100)W and bare (101), real $\mathrm{V} /(001) \mathrm{W}$ and real $\mathrm{V} /(100) \mathrm{W}$.

\section{CONCLUSIONS}

To summarize, DFT simulations, coupled to surface Pourbaix diagram, have been carried out to model, in realistic electrochemical conditions the HER reactions at differently terminated pristine and doped 
WC surfaces. The importance of considering the water effect during HER is demonstrated by comparing the HER performance on WC surfaces explicitly considering and neglecting it. Our results indicate that the water effect and the ensuing adsorption of $* \mathrm{O}$ and $* \mathrm{OH}$ can tune the HER activities by changing the hydrogen adsorption sites, the hydrogen adsorption ability, and exchange current densities. These results demonstrates the necessity of considering the water effect in the simulations and accordingly account for electrochemically deposited ${ }^{*} \mathrm{O}$ and $* \mathrm{OH}$ species. According to the DFT results, two WC surfaces can lead to industrially relevant exchange current densities, $(-100) \mathrm{W}\left(3.908 \mathrm{~mA} / \mathrm{cm}^{2}\right)$ and $(111) \mathrm{W}(0.133$ $\left.\mathrm{mA} / \mathrm{cm}^{2}\right)$. Surface substitutional doping $(\mathrm{V}, \mathrm{Mn}$, and $\mathrm{N})$ at the top layer has also been explored to quantify its potential for enhancing the HER activity on WC surfaces. We find the $\mathrm{V} /(001) \mathrm{W}\left(10.555 \mathrm{~mA} / \mathrm{cm}^{2}\right)$, $\mathrm{V} /(101)\left(1.730 \mathrm{~mA} / \mathrm{cm}^{2}\right), \mathrm{V} /(111) \mathrm{W}\left(0.876 \mathrm{~mA} / \mathrm{cm}^{2}\right), \mathrm{N} /(100) \mathrm{C}\left(0.258 \mathrm{~mA} / \mathrm{cm}^{2}\right)$, and $\mathrm{N} /(101)(0.636$ $\mathrm{mA} / \mathrm{cm}^{2}$ ) surfaces to result in exchange current densities larger than for most of the undoped WC surfaces. In addition, the calculated hydrogen coverage for HER on each surface suggests that adsorbed oxygen may also act as the catalytic site. The mechanisms through which water effects and doping can tune the HER activity has been rationalized on the basis of the atomic configurations of the catalytic surfaces, the changes of the catalytic sites, and the electronic properties related with the $d$-or $p$-band center of the top layer. Our results show that the water effect can weaken the strength of hydrogen adsorption on WC surfaces. $\mathrm{V}$, and $\mathrm{N}$ doping are found to result in similar weakening of the hydrogen adsorption capability for the doped surfaces, due to the shift of the $d$ - or $p$-band center. We expect the DFT results presented to provide timely and original guidelines for further theoretical and experimental studies on HER activity of WC related catalysts.

\section{SUPPORTING INFORMATION}

Methods of Surface Pourbaix Phase, Zero Point Energy, Atomic Structure of Hydrogen Adsorption, Data of Hydrogen Adsorption Ability $\left(\Delta G_{\mathrm{H}}\right)$

\section{AUTHOR INFORMATION}

*Email: lixibo@jnu.edu.cn

\section{CONFLICTS OF INTEREST}

There are no conflicts to declare.

\section{ACKNOWLEDGMENTS}

This work was supported by the National Natural Science Foundation of China (No. 21703081, 11804090), the Fundamental Research Funds for the Central Universities (No.21617330). The authors gratefully acknowledge the computational support by the High-Performance Super Computing Platform of Jinan University. G.T. acknowledge also support by the Royal Society Newton Advanced Fellowship scheme (grant No. NAF\R1\180242).

\section{REFERENCES}

1. Zou, X. ; Zhang, Y. Noble metal-free hydrogen evolution catalysts for water splitting. Chem. Soc. Rev. 2015, 44, 5148-5180.

2. Wang, P. ; Jiang, K. ; Wang, G. ; Yao, J. ; Huang, X. Phase and Interface Engineering of Platinum-Nickel Nanowires for Efficient Electrochemical Hydrogen 
Evolution. Angew. Chem., Int. Edit. 2016, 55, 12859-12863.

3. Sun, T. ; Wang, J. ; Chi, X. ; Lin, Y.; Chen, Z. ; Ling, X. ; Qiu, C. ; Xu, Y. ; Song, L. ; Chen, W. ; Su, C. Engineering the Electronic Structure of $\mathrm{MoS}_{2}$ Nanorods by $\mathrm{N}$ and Mn Dopants for U1tra-Efficient Hydrogen Production. ACS Catal. 2018, 8, 7585-7592.

4. Popczun, E. J. ; McKone, J. R. ; Read, C. G. ; Biacchi, A. J. ; Wiltrout, A. M. ; Lewis, N. S.; Schaak, R. E. Nanostructured nickel phosphide as an electrocatalyst for the hydrogen evolution reaction. J. Am. Chem. Soc. 2013, 135, 9267-9270.

5. Zhang, L. ; Li, M. ; Zou, A. ; Yu, S. H. ; Xiong, T. ; Wang, L. ; He, J. ; Fu, Q. ; Sun, K. ; Chua, D. H. Synergistically Configuring Intrinsic Activity and Fintube-like Architecture of $\mathrm{Mn}$-doped $\mathrm{MoS}_{2}$-based Catalyst for Improved Hydrogen Evolution Reaction. ACS App1. Energy Mater. 2018, 2, 493-502.

6. Yang, J. ; Wang, K. ; Zhu, J. ; Zhang, C. ; Liu, T. Self-templated growth of vertically aligned $2 \mathrm{H}-1 \mathrm{~T} \mathrm{MoS}_{2}$ for efficient electrocatalytic hydrogen evolution. ACS Appl. Mater. Inter. 2016, 8, 31702-31708.

7. Fan, X.-L. ; Yang, Y. ; Xiao, P. ; Lau, W. -M. Site-specific catalytic activity in exfoliated $\mathrm{MoS}_{2}$ single-layer polytypes for hydrogen evolution: basal plane and edges. J. Mater. Chem. A 2014, 2, 20545-20551.

8. Shi, Y. ; Zhang, B. Recent advances in transition metal phosphide nanomaterials: synthesis and applications in hydrogen evolution reaction. Chem. Soc. Rev. 2016, 45, 1529-1541.

9. Chen, W. -F. ; Muckerman, J. T. ; Fujita, E. Recent developments in transition metal carbides and nitrides as hydrogen evolution electrocatalysts. Chem. Commun. 2013, 49, 8896-8909.

10. Bonde, J. ; Moses, P. G.; Jarami11o, T. F.; Nørskov, J. K. ; Chorkendorff, I. Hydrogen evolution on nano-particulate transition metal sulfides. Faraday Discuss. 2009, 140, 219-231.

11. Meyer, S. ; Nikiforov, A. V. ; Petrushina, I. M. ; Köhler, K. ; Christensen, E. ; Jensen, J. 0. ; Bjerrum, N. J. Transition metal carbides (WC, $\mathrm{Mo}_{2} \mathrm{C}, \mathrm{TaC}, \mathrm{NbC}$ ) as potential electrocatalysts for the hydrogen evolution reaction (HER) at medium temperatures. Int. J. Hydrogen Energy 2015, 40, 2905-2911.

12. Cabán-Acevedo, M. ; Stone, M. L. ; Schmidt, J. ; Thomas, J. G. ; Ding, Q. ; Chang, H. -C. ; Tsai, M. -L. ; He, J.-H. ; Jin, S. Efficient hydrogen evolution catalysis using ternary pyrite-type cobalt phosphosulphide. Nat. Mater. 2015, 14, 12451251

13. Eftekhari, A. Electrocatalysts for hydrogen evolution reaction. Int. J. Hydrogen Energy 2017, 42, 11053-11077.

14. Lukowski, M. A. ; Daniel, A. S. ; Meng, F. ; Forticaux, A. ; Li, L. ; Jin, S. Enhanced hydrogen evolution catalysis from chemically exfoliated metallic $\mathrm{MoS}_{2}$ nanosheets. J. Am. Chem. Soc. 2013, 135, 10274-10277.

15. Prats, H. ; Piñero, J. J. ; Viñes, F. ; Bromley, S. T. ; Sayós, R. ; Illas, F. Assessing the usefulness of transition metal carbides for hydrogenation reactions. Chem. Commun. 2019, 55, 12797-12800.

16. Han, W. ; Chen, L. ; Ma, B. ; Wang, J. ; Song, W. ; Fan, X. ; Li, Y. ; Zhang, F. ; 
Peng, W. Ultra-small $\mathrm{Mo}_{2} \mathrm{C}$ nanodots encapsulated in nitrogen-doped porous carbon for pH-universal hydrogen evolution: insights into the synergistic enhancement of HER activity by nitrogen doping and structural defects. J. Mater. Chem. A 2019, 7, 4734-4743.

17. Xiong, J. ; Cai, W. ; Shi, W. ; Zhang, X. ; Li, J. ; Yang, Z. ; Feng, L. ; Cheng, H. Salt-templated synthesis of defect-rich MoN nanosheets for boosted hydrogen evolution reaction. J. Mater. Chem. A 2017, 5, 24193-24198.

18. Cui, Y.; Zhou, C. ; Li, X. ; Gao, Y.; Zhang, J. High performance electrocatalysis for hydrogen evolution reaction using nickel-doped $\mathrm{CoS}_{2}$ nanostructures: experimental and DFT insights. Electrochim. Acta 2017, 228, 428435.

19. Sperger, T. ; Sanhueza, I. A. ; Kalvet, I. ; Schoenebeck, F. Computational Studies of Synthetically Relevant Homogeneous Organometallic Catalysis Involving Ni, Pd, Ir, and Rh: An Overview of Commonly Employed DFT Methods and Mechanistic Insights. Chem. Rev. 2015, 115, 9532-9586.

20. Abghoui, Y.; Skúlason, E. Hydrogen Evolution Reaction Catalyzed by Transition-Metal Nitrides. J. Phys. Chem. C 2017, 121, 24036-24045.

21. Liang, Z. ; Zhong, X. ; Li, T. ; Chen, M. ; Feng, G. DFT Study on the Hydrogen Evolution Reaction for Different Facets of $\mathrm{Co}_{2} \mathrm{P}$. ChemElectroChem 2019, 6, 260267.

22. Zhang, Z. ; Yu, G. ; Li, H. ; Liu, J. ; Huang, X. ; Chen, W. Theoretical insights into the effective hydrogen evolution on $\mathrm{Cu}_{3} \mathrm{P}$ and its evident improvement by surface-doped Ni atoms. Phys. Chem. Chem. Phys. 2018, 20, 10407-10417.

23. Wang, Z. ; Luo, H. ; Lin, R. ; Lei, H. ; Yuan, Y. ; Zhu, Z. ; Li, X. ; Mai, W. Theoretical calculation guided electrocatalysts design: Nitrogen saturated porous $\mathrm{Mo}_{2} \mathrm{C}$ nanostructures for hydrogen production. App1. Catal., B 2019, 257, 117891.

24. Levy, R. ; Boudart, M. Platinum-like behavior of tungsten carbide in surface catalysis. Science 1973, 181 547-549.

25. Esposito, D. V.; Hunt, S. T. ; Kimme1, Y. C. ; Chen, J. G. A New Class of Electrocatalysts for Hydrogen Production from Water Electrolysis: Metal Monolayers Supported on Low-Cost Transition Metal Carbides. J. Am. Chem. Soc. 2012, 134, 3025-3033.

26. Michalsky, R. ; Zhang, Y.-J. ; Peterson, A. A. Trends in the hydrogen evolution activity of metal carbide catalysts. ACS Catal. 2014, 4, 1274-1278.

27. Ham, D. J. ; Ganesan, R. ; Lee, J. S. Tungsten carbide microsphere as an electrode for cathodic hydrogen evolution from water. Int. J. Hydrogen Energy 2008, 33, 6865-6872.

28. Kimme1, Y. C. ; Esposito, D. V. ; Birkmire, R. W. ; Chen, J. G. Effect of surface carbon on the hydrogen evolution reactivity of tungsten carbide (WC) and Pt-modified WC electrocatalysts. Int. J. Hydrogen Energy 2012, 37, 3019-3024.

29. Tang, C. ; Wang, D. ; Wu, Z. ; Duan, B. Tungsten carbide hollow microspheres as electrocatalyst and platinum support for hydrogen evolution reaction. Int. J. Hydrogen Energy 2015, 40, 3229-3237. 
30. Emin, S.; Altinkaya, C. ; Semerci, A. ; Okuyucu, H. ; Yildiz, A. ; Stefanov, P. Tungsten carbide electrocatalysts prepared from metallic tungsten nanoparticles for efficient hydrogen evolution. Appl. Catal., B 2018, 236, 147-153.

31. Tomás-García, A. L. ; Jensen, J. 0. ; Bjerrum, N. J. ; Li, Q. Hydrogen evolution activity and electrochemical stability of selected transition metal carbides in concentrated phosphoric acid. Electrochim. Acta 2014, 137, 639-646.

32. Esposito, D. V. ; Hunt, S. T. ; Stottlemyer, A. L. ; Dobson, K. D. ; McCandless, B. E. ; Birkmire, R. W. ; Chen, J. G. Low - cost hydrogen - evolution catalysts based on monolayer platinum on tungsten monocarbide substrates. Angew. Chem., Int. Ed. 2010, 49, 9859-9862.

33. Yan, Z.; Cai, M. ; Shen, P. K. Nanosized tungsten carbide synthesized by a novel route at low temperature for high performance electrocatalysis. Sci. Rep. 2013, 3, 1646.

34. Harnisch, F. ; Sievers, G. ; Schröder, U. Tungsten carbide as electrocatalyst for the hydrogen evolution reaction in $\mathrm{pH}$ neutral electrolyte solutions. Appl. Catal., B 2009, 89, 455-458.

35. Armstrong, R. D. ; Be11, M. F. Tungsten carbide catalysts for hydrogen evolution. Electrochim. Acta 1978, 23, 1111-1115.

36. Yu, G. -Q. ; Huang, B. -Y. ; Chen, X. ; Wang, D. ; Zheng, F. ; Li, X.-B. Uncovering the Surface and Phase Effect of Molybdenum Carbides on Hydrogen Evolution: A First-Principles Study. J. Phys. Chem. C 2019, 123, 21878-21887.

37. Hansen, M. H. ; Stern, L. -A. ; Feng, L. ; Rossmeis1, J. ; Hu, X. Widely available active sites on $\mathrm{Ni}_{2} \mathrm{P}$ for electrochemical hydrogen evolution - insights from first principles calculations. Phys. Chem. Chem. Phys. 2015, 17, 10823-10829.

38. Han, N. ; Yang, K. R. ; Lu, Z. ; Li, Y. ; Xu, W. ; Gao, T. ; Cai, Z. ; Zhang, Y. ; Batista, V. S. ; Liu, W. ; Sun, X. Nitrogen-doped tungsten carbide nanoarray as an efficient bifunctional electrocatalyst for water splitting in acid. Nat. Commun. 2018, 9, 924.

39. Ma, Y. -Y. ; Lang, Z. -L. ; Yan, L.-K. ; Wang, Y.-H. ; Tan, H. -Q. ; Feng, K. ; Xia, Y.-J. ; Zhong, J. ; Liu, Y. ; Kang, Z.-H. Highly efficient hydrogen evolution triggered by a multi-interfacial Ni/WC hybrid electrocatalyst. Energy Environ. Sci. 2018, 11, 2114-2123.

40. Kresse, G. ; Furthmüller, J. Efficient iterative schemes for ab initio totalenergy calculations using a plane-wave basis set. Phys. Rev. B: Condens. Matter Mater. Phys 1996, 54, 11169-11186.

41. Klimeš, J. ; Bowler, D. R.; Michaelides, A. Van der Waals density functionals applied to solids. Phys. Rev. B 2011, 83, 195131.

42. Monkhorst, H. J.; Pack, J. D. Special points for Brillouin-zone integrations. Phys. Rev. B 1976, 13, 5188-5192.

43. Hansen, H. A. ; Rossmeis1, J. ; Nørskov, J. K. Surface Pourbaix diagrams and oxygen reduction activity of $\mathrm{Pt}, \mathrm{Ag}$ and $\mathrm{Ni}(111)$ surfaces studied by DFT. Phys. Chem. Chem. Phys. 2008, 10, 3722-3730.

44. Li, X.-B. ; Cao, T. ; Zheng, F. ; Chen, X. Computational Screening of Electrocatalytic Materials for Hydrogen Evolution: Platinum Monolayer on 
Transitional Metals. J. Phys. Chem. C 2019, 123, 495-503.

45. Wexler, R. B. ; Martirez, J. M. P. ; Rappe, A. M. , Stable Phosphorus-Enriched (0001) Surfaces of Nickel Phosphides. Chem. Mater. 2016, 28, 5365-5372.

46. Zheng, J. ; Sheng, W. ; Zhuang, Z. ; Xu, B. ; Yan, Y. Universal dependence of hydrogen oxidation and evolution reaction activity of platinum-group metals on pH and hydrogen binding energy. Sci. Adv. 2016, 2, e1501602-e1501602.

47. Zheng, Y.; Jiao, Y. ; Vasileff, A. ; Qiao; S. -Z. The Hydrogen Evolution Reaction in Alkaline Solution: From Theory, Single Crystal Models, to Practical Electrocatalysts. Angew. Chem., Int. Ed. 2018, 57, 7568.

48. Nørskov, J. K. ; Bligaard, T. ; Logadottir, A. ; Kitchin, J. R. ; Chen, J. G. ; Pandelov, S. ; Stimming, U. Trends in the Exchange Current for Hydrogen Evolution.

J. Electrochem. Soc. 2005, 152, J23.

49. Bi, K. ; Liu, J. ; Dai, Q. First-principles study of boron, carbon and nitrogen adsorption on WC ( $\left.\begin{array}{lll}1 & 0 & 0\end{array}\right)$ surface. Appl. Surf. Sci. 2012, 258, 4581-4587.

50. Kurlov, A. S. ; Gusev, A. I. Phase equilibria in the $\mathrm{W}-\mathrm{C}$ system and tungsten carbides. Russ. Chem. Rev. 2006, 75, 617.

51. Bajdich, M. ; García-Mota, M. ; Vojvodic, A. ; Nørskov, J. K. ; Be11, A. T. Theoretical investigation of the activity of cobalt oxides for the electrochemical oxidation of water. J. Am. Chem. Soc. 2013, 135, 13521-13530.

52. Rong, X. ; Kolpak, A. M. Ab initio approach for prediction of oxide surface structure, stoichiometry, and electrocatalytic activity in aqueous solution. $J$. Phys. Chem. Lett. 2015, 6, 1785-1789.

53. He, J. ; Cui, Z. ; Zhu, S. ; Li, Z. ; Wu, S. ; Zheng, L. ; Gao, Z. ; Liang, Y., Insight into the Electrochemical-Cycling Activation of Pt/Molybdenum Carbide toward Synergistic Hydrogen Evolution Catalysis. J. Catal. 2020, 384, 169-176.

54. Yang, H. ; Ma, Y. ; Lv, X. ; Huang, B. ; Dai, Y., Prediction of Intrinsic

Electrocatalytic Activity for Hydrogen Evolution Reaction in $\mathrm{Ti}_{4} \mathrm{X}_{3}(\mathrm{X}=\mathrm{C}, \mathrm{N}) . J$.

Catal. 2020, 387, 12-16.

55. Greeley, J.; Nørskov, J. K. ; Mavrikakis, M., Electronic Structure and Catalysis on Metal Surfaces. Annu. Rev. Phys. Chem. 2002, 53, 319-348.

56. Xin, H. ; Linic, S. Communications: Exceptions to the $d$-band model of chemisorption on metal surfaces: The dominant role of repulsion between adsorbate states and metal $d$-states. J. Chem. Phys. 2010, 132, 221101.

57. Pei, W. ; Zhou, S. ; Bai, Y. ; Zhao, J., N-Doped Graphitic Carbon Materials Hybridized with Transition Metals (Compounds) for Hydrogen Evolution Reaction: Understanding the Synergistic Effect from Atomistic Level. Carbon 2018, 133, 260-266.

58. Lee, Y.-L. ; Kleis, J. ; Rossmeisl, J. ; Shao-Horn, Y.; Morgan, D., Prediction of Solid 0xide Fuel Cell Cathode Activity with First-Principles Descriptors. Energy Environ. Sci. 2011, 4, 3966-3970.

59. Chen, C. ; Baiyee, Z. M. ; Ciucci, F., Unraveling the Effect of La a-Site Substitution on 0xygen Ion Diffusion and 0xygen Catalysis in Perovskite Bafeo3 by Data-Mining Molecular Dynamics and Density Functional Theory. Phys. Chem. Chem. Phys. 2015, 17, 24011-24019. 


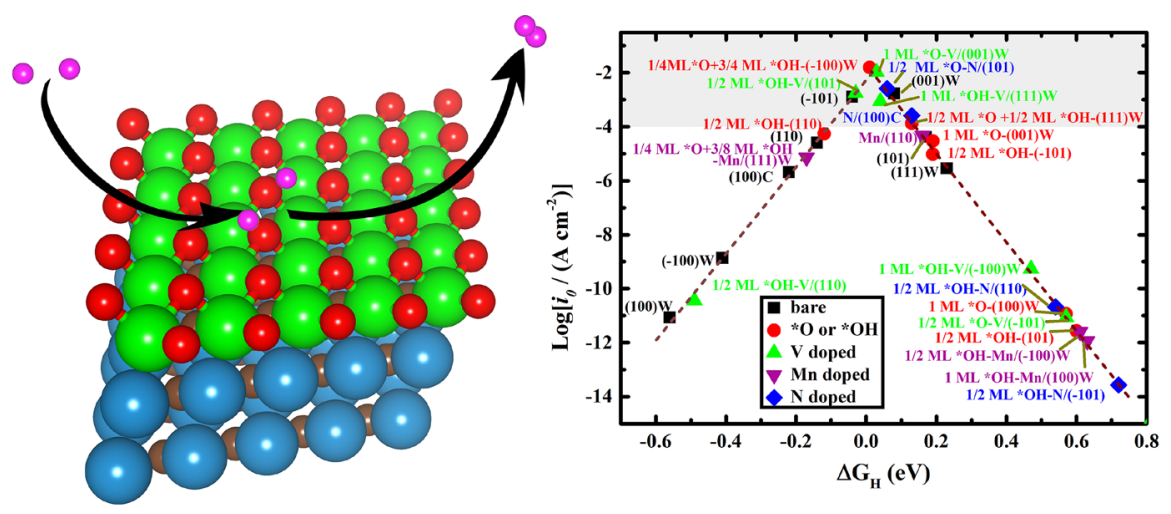

TOC Graphic 